\title{
Petroleum hydrocarbon rich oil refinery sludge of North-East India harbours anaerobic, fermentative, sulfate-reducing, syntrophic and methanogenic microbial populations
}

Ajoy Roy ${ }^{1}$, Pinaki Sar ${ }^{2}$, Jayeeta Sarkar², Avishek Dutta ${ }^{2,3}$, Poulomi Sarkar², Abhishek Gupta², Balaram Mohapatra², Siddhartha Pal ${ }^{1}$ and Sufia K Kazy ${ }^{1 *}$

\begin{abstract}
Background: Sustainable management of voluminous and hazardous oily sludge produced by petroleum refineries remains a challenging problem worldwide. Characterization of microbial communities of petroleum contaminated sites has been considered as the essential prerequisite for implementation of suitable bioremediation strategies. Three petroleum refinery sludge samples from North Eastern India were analyzed using next-generation sequencing technology to explore the diversity and functional potential of inhabitant microorganisms and scope for their onsite bioremediation,

Results: All sludge samples were hydrocarbon rich, anaerobic and reduced with sulfate as major anion and several heavy metals. High throughput sequencing of V3-16S rRNA genes from sludge metagenomes revealed dominance of strictly anaerobic, fermentative, thermophilic, sulfate-reducing bacteria affiliated to Coprothermobacter, Fervidobacterium, Treponema, Syntrophus, Thermodesulfovibrio, Anaerolinea, Syntrophobacter, Anaerostipes, Anaerobaculum, etc., which have been well known for hydrocarbon degradation. Relatively higher proportions of archaea were detected by qPCR. Archaeal 165 rRNA gene sequences showed presence of methanogenic Methanobacterium, Methanosaeta, Thermoplasmatales, etc. Detection of known hydrocarbon utilizing aerobic/facultative anaerobic (Mycobacterium, Pseudomonas, Longilinea, Geobacter, etc.), nitrate reducing (Gordonia, Novosphigobium, etc.) and nitrogen fixing (Azovibrio, Rhodobacter, etc.) bacteria suggested niche specific guilds with aerobic, facultative anaerobic and strict anaerobic populations. Phylogenetic Investigation of Communities by Reconstruction of Unobserved States (PICRUSt) predicted putative genetic repertoire of sludge microbiomes and their potential for hydrocarbon degradation; lipid-, nitrogen-, sulfur- and methane- metabolism. Methyl coenzyme M reductase A ( $m c r A$ ) and dissimilatory sulfite reductase beta-subunit (dsrB) genes phylogeny confirmed methanogenic and sulfate-reducing activities within sludge environment endowed by hydrogenotrophic methanogens and sulfate-reducing Deltaproteobacteria and Firmicutes members.
\end{abstract}

Conclusion: Refinery sludge microbiomes were comprised of hydrocarbon degrading, fermentative, sulfatereducing, syntrophic, nitrogen fixing and methanogenic microorganisms, which were in accordance with the prevailing physicochemical nature of the samples. Analysis of functional biomarker genes ascertained the activities of methanogenic and sulfate-reducing organisms within sludge environment. Overall data provided better insights on microbial diversity and activity in oil contaminated environment, which could be exploited suitably for in situ bioremediation of refinery sludge.

Keywords: Refinery sludge, Microbial diversity, Total petroleum hydrocarbon, PICRUSt, Bioremediation

\footnotetext{
* Correspondence: sufia_kazy@yahoo.com

'Department of Biotechnology, National Institute of Technology Durgapur,

Durgapur, WB 713 209, India

Full list of author information is available at the end of the article
}

(c) The Author(s). 2018 Open Access This article is distributed under the terms of the Creative Commons Attribution 4.0 International License (http://creativecommons.org/licenses/by/4.0/), which permits unrestricted use, distribution, and reproduction in any medium, provided you give appropriate credit to the original author(s) and the source, provide a link to the Creative Commons license, and indicate if changes were made. The Creative Commons Public Domain Dedication waiver (http://creativecommons.org/publicdomain/zero/1.0/) applies to the data made available in this article, unless otherwise stated. 


\section{Background}

Petroleum industries generate huge quantities of oily sludge containing various hydrocarbons and other recalcitrant compounds which may lead to severe environmental pollution due to its wide distribution, persistence and toxic nature $[1,2]$. It has been estimated that around $8 \times 10^{4}$ to $1 \times 10^{7}$ tons of petroleum hydrocarbons will be globally released per year [3]. In India, more than 28,000 tons of oil containing sludge is generated annually by oil refineries [4]. Management and disposal of such hazardous waste remain a challenging problem worldwide. Over the years various physical and chemical methods have been developed for the treatment of oil-impacted sludge/ environment. Nevertheless, eco-friendly, cost-effective and sustainable microbe-based in situ bioremediation of contaminated sites has gained considerable importance, as bioremediation technology is relying on the metabolic activity of the native microbial populations contributing in hydrocarbon mineralization through natural biogeochemical cycles $[5,6]$. However, the diversity, distribution and activity of native microbial communities are determined by the prevailing environmental factors of the contaminated sites to thrive in such inhospitable conditions $[7,8]$. Therefore, characterization of contaminated sites and inhabitant microbial populations have been considered as essential prerequisites for the development of bioremediation strategies as the success of bioremediation is very much influenced by the available physicochemical conditions and nutrient availability [9-11]. Bioremediation efficiency could be accelerated either by stimulating the metabolic activity of native microorganisms by nutrient amendments and/or by alterations in physicochemical conditions or by introducing more efficient microbes isolated from exogenous or endogenous sources [12-14].

Extensive culture-independent molecular investigations have revealed complex assemblages of diverse groups of aerobic and anaerobic microorganisms capable of various hydrocarbon degradation, nitrate-/sulfate -/metal-reduction, fermentation, syntrophism and methane metabolism in different oil-associated environments [10, 15-18]. Advanced meta-omics technologies have also demonstrated strong metabolic interactions within existing community owing to co-existence of diverse hydrocarbon-degrading microbial groups and catabolic genes related to aerobic and anaerobic degradation, nutrient metabolism and biogeochemical cycles in oil-associated environments [6, 19-25]. Several hydrocarbon metabolizing bacteria under the genera Pseudomonas, Rhodococcus, Acinetobacter, Burkholderia, Sphingomonas, Alcanivorax, Marinobacter, Cycloclasticus, etc., and their relevant catabolic genes have been well documented by previous investigators [10, 18-20, 22, 23, 26-28]. Recently, $\mathrm{Hu}$ et al., [29] revealed the potential roles of various candidate phyla like OP11, OP9,
OD1, TA06, WS6 and SAR406 in the biogeochemical transformation of petroleum oils. Significant contributions of archaeal community in petroleum-contaminated environments have been established [30]. Ghosal et al., [18] have reported archaea as one of the six key members with hydrocarbon metabolizing properties along with Alphaproteobacteria, Betaproteobacteria, Gammaproteobacteria, Actinomycetes and Firmicutes. Many members of Deltaproteobacteria are known to be involved in anaerobic hydrocarbon degradation and their abundance often increased with petroleum hydrocarbon contamination [27, 31]. In recent years, high throughput sequencing technologies revealed the presence and the importance of less abundant rare microbial groups for maintaining ecosystem functions in diverse habitats. Obligate hydrocarbonoclastic bacteria are considered as "conditionally rare taxa" as these organisms showed huge abundance after drastic environmental perturbations due to oil spills [2]. Previous investigators have successfully used various functional biomarker genes such as alkane monooxygenase (alkB, which catalyses hydroxylation of alkanes), naphthalene dioxygenase (ndo, involved in hydroxylation of aromatic hydrocarbons), benzyl succinate synthase (bss A, anaerobic toluene degradation), methyl coenzyme $\mathrm{M}$ reductase $\mathrm{A}$ ( $m c r A$, involved in the terminal step in anaerobic methane production) and dissimilatory sulfite reductase genes ( $d s r \mathrm{~A}$ and $d s r \mathrm{~B}$, involved in dissimilatory sulfite reduction and often associated with mineralization of organic compounds) to assess the catabolic potential of native microbial populations and the magnitude of contamination at the polluted sites [20, 25, 32-38]. Quantitative PCR (qPCR) based studies on such functional biomarkers have demonstrated the relationship between the abundance/expression of genes and biodegradation of contaminants [3, 26, 33]. Dombrowski et al., [39] proposed metabolic linkages amongst different functional groups, like fermentative members of the community which have substrate-level interdependencies with sulfurand nitrogen-cycling microorganisms.

Extensive research has elucidated microbial communities from a variety of hydrocarbon contaminated environments including deep water horizon spill, oil contaminated soil or sediments, drill cuttings, production and injection water, etc. $[3,19-23,26,27,37,39$, 40]. However, investigation on petroleum refinery waste sludge microbiome remained little explored. The present work was undertaken to explore the native microbial community composition and function in oil containing sludge of Guwahati and Digboi refineries, Assam, India, by adopting following approaches -i) $16 \mathrm{~S}$ rRNA amplicon sequencing of sludge microbial communities using Illumina next-generation sequencing platform, ii) assessment of inherent microbial metabolic potentials using functional biomarker genes ( $m c r \mathrm{~A}$ and $d s r \mathrm{~B})$ through 
clone library and qPCR based studies and iii) predictive functional profiling of sludge microbial communities using PICRUSt. Our study provided deeper insights into the native microbial community composition and function in oily sludge, which might be exploited for in situ bioremediation of such petroleum refinery waste.

\section{Methods}

Sample collection, physicochemical analysis, and enumeration of microorganisms

Refinery waste sludge samples were collected in sterile screw-capped glass bottles (1 l capacity) using sterilized stainless steel scoops from storage tank/pit of Indian Oil Corporation Limited (IOCL) at Guwahati $\left(26.18^{\circ} \mathrm{N}\right.$, $91.80^{\circ} \mathrm{E}$ and $26.14^{\circ} \mathrm{N}, \mathrm{E} 91.73^{\circ} \mathrm{E}$, designated as GR1 and GR3 respectively) and Digboi $\left(27.39^{\circ} \mathrm{N}, 95.61^{\circ} \mathrm{E}\right.$ designated as DB2), Assam, India and immediately stored in ice. Sludge samples were collected from nearly $30-50 \mathrm{~cm}$ below the top surface. Three to five subsamples were collected from each location and pooled together. The samples were immediately stored in sterile glass bottles (Schott Duran, Germany) at a temperature below $4{ }^{\circ} \mathrm{C}$. All containers were sterile and nuclease-free. Physicochemical parameters including $\mathrm{pH}$, temperature, oxidation-reduction potential (ORP), dissolved oxygen (DO) and conductivity of the samples were measured on site using an Orion Star 140 TM series meter (Thermo Electron Corporation, USA). The samples were stored at $4{ }^{\circ} \mathrm{C}$ after reaching laboratory.

Key anions $\left(\mathrm{SO}_{4}{ }^{2-}, \mathrm{NO}_{3}{ }^{-}, \mathrm{NO}_{2}{ }^{-}, \mathrm{PO}_{4}{ }^{3-}, \mathrm{Cl}^{-}\right)$were estimated by spectrophotometric and titrimetric methods (as appropriate) of American Public Health Association (APHA; methods 4500 and 2320B). Major metallic elements (Fe, $\mathrm{Ni}, \mathrm{Pb}, \mathrm{Zn}, \mathrm{Na}, \mathrm{K}, \mathrm{Cd}$ ) were estimated using inductively coupled plasma mass spectrophotometer (ICP-MS) (Varian 810 ICP-MS System, USA) following acid digestion (EPA protocol 3050B). Estimation of total petroleum hydrocarbon (TPH), as well as constituent hydrocarbons, was done by gravimetric method followed by gas chromatograph coupled with mass spectrometer (GC-MS) (Perkin Elmer Clarus 680, USA) analysis. Elite $5 \mathrm{MS}$ column $(30 \mathrm{~m} \times 0.25 \mathrm{~mm}$ id, film thickness $0.25 \mu \mathrm{m})$ was used along with helium as a carrier gas (flow rate $1 \mathrm{ml} \mathrm{min}{ }^{-1}$ ). The injector temperature was set at $260{ }^{\circ} \mathrm{C}$. The oven temperature was initially set at $50^{\circ} \mathrm{C}$ for $2 \mathrm{~min}$ and then increased to $60{ }^{\circ} \mathrm{C}$ at the rate of $2{ }^{\circ} \mathrm{C} \mathrm{min}^{-1}$ and maintained for $2 \mathrm{~min}$, subsequently raised to $210^{\circ} \mathrm{C}$ at $3^{\circ}$ $\mathrm{C} \mathrm{min}^{-1}$ and maintained for $2 \mathrm{~min}$. Finally the oven temperature was raised to $270{ }^{\circ} \mathrm{C}$ at the rate of $10^{\circ}$ $\mathrm{C} \mathrm{min}^{-1}$ and maintained for $7 \mathrm{~min}$. The conditions for mass spectrophotometer operation were set as: ion source temperature, $200{ }^{\circ} \mathrm{C}$; transfer line temperature was $280^{\circ} \mathrm{C}$; the mass range was 40-600 a.m.u (Atomic Mass Unit). Identification of the components was carried out by comparing the mass spectrum of the component to that of the mass spectral library from NIST 14. (National Institute of Standards and Technology, USA).

Total bacterial counts were ascertained using fluorescence microscopy following the protocol described by Kepner and Pratt [41]. Briefly, cells were dislodged from $0.1 \mathrm{~g}$ sample using $5 \mathrm{ml}$ sterile sodium pyrophosphate $(0.1 \% \mathrm{w} / \mathrm{v})$, fixed with $4 \%$ paraformaldehyde and incubated at $4{ }^{\circ} \mathrm{C}$ for $4 \mathrm{~h}$. Fixed cells were centrifuged $(10,000 \mathrm{rpm}$ for $5 \mathrm{~min}$ ) and washed thrice in phosphate buffered saline (PBS) solution (pH 7.2). Staining was achieved using 0.1\% $(w / v)$ acridine orange (AO) to the resulting pellet and incubation in dark for 15 min. Excess of AO was washed with PBS and cells were visualized under Olympus CKX41 (Japan) inverted microscope at 1000X magnification with oil immersion. The software ImageJ (http:// rsbweb.nih.gov/ij/) was used for quantification of cells. Enumeration of aerobic and anaerobic heterotrophic cell counts was done by resuspending $0.1 \mathrm{~g}$ of each sample in $9 \mathrm{ml}$ sterile sodium pyrophosphate $(0.1 \% \mathrm{w} / \mathrm{v})$, followed by dilution of the extracted liquid up to $10^{-4}$ using $0.9 \%(w /$ $v$ ) sterile saline. Finally the diluted samples were spread on Reasoner's 2A (R2A), Minimal Salt Medium (MSM) agar and anaerobic agar (Himedia, India) [42]. For aerobic bacterial counts, R2A and MSM agar plates were incubated at $30{ }^{\circ} \mathrm{C}$ for 2 days. For anaerobic bacterial counts, anaerobic agar plates were incubated at $30{ }^{\circ} \mathrm{C}$ for 15 days in an anaerobic jar with the anaerobic gas pack (Himedia, India). Aerobic and anaerobic colonies were counted after 2 and 15 days, respectively.

\section{Community level physiological profiling (CLPP)}

Functional potential of the microbial communities was investigated by community level physiological profiling (using Biolog ECO plate). Cells were dislodged from the samples using $1 \%(w / v)$ sodium pyrophosphate. $150 \mu \mathrm{l}$ of the resulting cell suspension was inoculated in each well of the Biolog ECO plate and incubated at $30{ }^{\circ} \mathrm{C}$. Along with the three waste sludge samples, a garden soil was taken as control (to appraise the possible effect of high $\mathrm{TPH}$ in substrate utilization). Utilization of substrates was measured by monitoring the optical density of each well at $590 \mathrm{~nm}$, at an interval of every $12 \mathrm{~h}$ over 7 days. The average well color development (AWCD) was estimated according to the following equations:

$$
\mathrm{AWCD}=\sum_{\mathrm{i}=0}^{31} \mathrm{OD}_{\mathrm{i}} / 31
$$

Metagenome extraction and sequencing of 16S rRNA genes Total community DNA was extracted from each sample $(250 \mathrm{mg})$ in triplicate using MoBioPowerSoil ${ }^{\text {Tw }}$ DNA extraction kit (MoBio, USA) according to the 
manufacturer's instructions with slight modifications. Bead beating of the sample was done thrice for $5 \mathrm{~min}$ with an interval of $5 \mathrm{~min}$. At the final step the DNA was eluted in nuclease free water. During elution of DNA from the spin column, after addition of water in the column it was incubated for half an hour which improved the DNA yield. The metagenomes were extracted at least 10 times from each sample and all the extractions were pooled together before amplicon sequencing. The DNA was quantified using Nanodrop spectrophotometer (Nano 2000 Thermo Fischer Scientific, USA) as well as Qubit fluorometer (Qubit 3.0 Fluorometer Applied Biosystem, USA) with $\mathrm{A}_{260 / 280}$ was in the range of 1.79-1.81. Microbial community in each sample was analyzed using Illumina based $16 \mathrm{~S}$ rRNA gene (V3 region) amplicon sequencing. NGS services of Genotypic Technology Pvt. Ltd., Bangalore, India and SciGenome Labs, Chennai, India were used.

\section{Bioinformatic data analysis}

Microbial diversity in terms of taxonomic groups as well as their abundance was determined using Quantitative Insights into Microbial Ecology (QIIME) version 1.9.1 [43] following Bartram et al. [44]. Paired-end raw reads obtained through Illumina sequencing of V3 region of $16 \mathrm{~S}$ rRNA gene were merged into single end reads using FLASH (Fast Length Adjustment of Short Reads) with a minimum overlap of $8 \mathrm{bp}$ and maximum mismatch density of 0.1 followed by conversion of the fastq file to their corresponding sequence and quality (.fna and .qual) files [45]. The sequence files were quality filtered using split_libraries.py. OTU (Operational Taxonomic Unit) picking and taxonomy assignment was done using pick_de_novo_otus.py with default parameters. Greengenes 13.8 database was used as a reference database for taxonomy assignment. Alpha diversity indices (Chao1, Shannon, Simpson, Good's coverage and Observed species) as well as rarefaction curves were also estimated.

Venn diagrams were constructed to forecast the number of unique and shared entries at each taxonomic level viz., OTU, phyla, class, family and genus among the sludge samples using Venny 2.1 (http://bioinfogp.cnb.csic.es/tools/ venny/). Weighted Pair Group Method with Arithmetic Mean (WPGMA) analysis of families (with cumulative abundance $\leq 0.2 \%$ abundance) based on Bray-Curtis dissimilarity index was done by MVSP (Multivariate Statistical Package).

Top 50 OTUs were selected on the basis of their cumulative abundances across all the samples and heat map was constructed on the basis of Pearson correlation using METAGENassist [46].

Comparison of microbial communities of different petroleum hydrocarbon contaminated environments

Microbial community compositions (phylum level) of the test sludge samples were compared with fifteen other previously reported petroleum hydrocarbon contaminated environments. An UPGMA was performed among the samples using Euclidean similarity indices by using PAST3 software.

Function prediction and metabolic pathway reconstruction PICRUSt was used to predict the genomic repertoire of each community metagenome [47]. For PICRUSt analysis, the pick_closed_reference_otus.py command in QIIME was used with Greengenes version 13.5 as a reference database for OTU picking and the resulting OTU biom table was uploaded in the Galaxy server (https://huttenho wer.sph.harvard.edu/galaxy/).This software assigns the functional features by comparing the identified 16S rRNA gene sequence with that of the closest match of the known genome sequence. Metagenome function was predicted with NSTI (Nearest Sequenced Taxon Index) values followed by the metabolic pathway reconstruction using KEGG (Kyoto Encyclopedia of Genes and Genomes) database. To calculate the closeness with known sequenced genomes, an indicator, nearest sequenced taxon index (NSTI), was calculated, wherein, a value close to 0 indicates high similarity to a closest sequenced taxon, whereas nearer to 1 indicates no significant similarity.

\section{Analysis of archaeal populations}

To assess the archaeal diversity of the samples, archaeal specific 16S rRNA genes were PCR amplified from metagenome, cloned and clone libraries were analyzed through Sanger sequencing. Details of the primers used for amplification of archaebacterial 16S rRNA genes and PCR conditions are presented in Additional file 1: Table S1. Agarose gel purified PCR products of $16 \mathrm{~S}$ rRNA genes were ligated into $\mathrm{pTZ57R/T}$ vector (Promega, USA) and transformed into $E$. coli $\mathrm{DH} 10 \beta$ following the manufacturer's instructions. Randomly chosen (100120) positive colonies per samples were picked up and analyzed for desired insert size. The cloned 16S rRNA gene fragments from each positive colony were re-amplified using vector specific primer M13F and M13R. Each library was subjected to ARDRA (Amplified Ribosomal DNA Restriction Analysis). The amplified products were digested with restriction endonucleases (HaeIII and MspI) in separate reactions. All digests were analyzed by $2.5 \%$ agarose gel electrophoresis [42]. ARDRA patterns were grouped visually and each group was referred as an OTU or ribotype. Plasmid DNA was isolated from selected clones of different OTUs using HiPura Plasmid DNA extraction kit (Himedia, India) according to the manufacturer's instructions. Sequencing of the plasmid was done using M13R primer by Eurofins Genomics India Pvt. Ltd. For each sequence, closest sequences were retrieved from those available in public database by using the BLAST 
(NCBI) program (http://blast.ncbi.nlm.nih.gov/Blast.cgi) followed by initial classification using a web-based classifier program in ribosomal database project (RDP released 11 and with $95 \%$ of similarity) (http://rdp.cme.msu.edu/classifier/classifier.jsp). The phylogenetic tree was constructed using MEGA 5 with the neighbor-joining method [48].

\section{Real-time (qPCR) based quantification of bacterial- and archaeal 16S rRNA genes and mcrA and $d s r B$ genes}

Real-time q-PCR based on fluorescent dye SYBR green was used to quantify bacterial and archaeial 16S rRNA gene copies as well as the genes encoding methyl coenzyme $\mathrm{M}$ reductase $(\mathrm{mcr} \mathrm{A})$ and dissimilarity sulfite reduction $(d s r \mathrm{~B})$. Primer sequences used, amplification product sizes and annealing temperatures for respective genes are tabulated in Additional file 1: Table S1. Real-time PCR standard curves were prepared for absolute determination of copy number of each of the four genes. Each of the genes were PCR amplified from metagenome, cloned and positive clones containing correct inserts were used for plasmid extraction. Extracted and purified plasmids were re-sequenced for confirming the integrity of the cloned gene and then used as a standard for real-time PCR analysis.

Copy no. of each plasmid was calculated using the formulae:

No.of copies $/ \mu \mathrm{L}=\frac{(\text { Conc.of plasmid }[\mathrm{ng} / \mu \mathrm{L}] \times \text { Avogadro No. })}{\left(\text { Size of plasmid } \times 660 \times 10^{9}\right)}$

Standard curves were prepared for each gene with $10^{-}$ ${ }^{2}-10^{-8}$ dilutions of the original plasmid. Because lengths of the vector and target gene inserts were known, gene copy numbers could be estimated. Quantification was carried out on a QuantStudio 5 real-time PCR (Thermo-Fisher, USA) using QuantIt ${ }^{\circ}$ SYBR green PCR master mix (Applied Biosystem, USA) following the manufacturer's directions. Reaction mixtures $(10 \mu \mathrm{L})$ contained $5 \mu \mathrm{L}$ of $2 X$ SYBR Green qPCR master mix, $0.5 \mu \mathrm{l}$ for both the forward and reverse primer, pre-sequenced plasmids containing gene of interest and sample DNA as a template for standard curve preparation and gene quantification, respectively. Cycling conditions for real-time qPCR were as follows: hold for $10 \mathrm{~min}$ at $94{ }^{\circ} \mathrm{C}$ followed by 40 cycles of denaturing at $94{ }^{\circ} \mathrm{C}$ for $15 \mathrm{~s}$, annealing at $55^{\circ} \mathrm{C}$ for $15 \mathrm{~s}$ and extension at $72{ }^{\circ} \mathrm{C}$ for $15 \mathrm{~s}$; followed by a melting curve from $55^{\circ} \mathrm{C}$ to $95^{\circ} \mathrm{C}$ (increment $=0.5^{\circ} \mathrm{C}$ per $10 \mathrm{~s}$ ). All samples were run in triplicate and melting curve of products was analyzed in order to monitor non-specific amplification or primer-dimers.

\section{Analysis of $m c r A$ and $d s r B$ genes}

Nature and function of two important functional genes encoding the alpha subunit of methyl coenzyme $M$ reductase $(m c r A)$ and dissimilatory sulfite reductase subunit $\mathrm{B}$ $(d s r \mathrm{~B})$ were targeted to gain insight into the metabolic diversity in the petroleum-rich samples. $m c r A$ gene was amplified using the specific primer pair ME1 and ME2. To elucidate the sulfate-reducing populations of the samples, clone library of the $d s r \mathrm{~B}$ gene was constructed using gene-specific primers p2060F and 4R. Details of the primers used for each gene and PCR conditions are presented in Additional file 1: Table S1. Amplified PCR products were analyzed on $1 \%$ agarose gel; PCR products of $m c r \mathrm{~A}$ and $d s r \mathrm{~B}$ genes were gel purified (QIAquick gel extraction kit, Netherlands), resuspended in nuclease-free water and ligated into pTZ57R/T vector (Promega, USA). Ligated vectors were transformed into $E$. coli $\mathrm{DH} 10 \beta$ following the manufacturer's instructions. Randomly chosen positive colonies were analyzed for desired insert size. Plasmid DNA was extracted from selected clones and sequencing of the inserted gene was done using M13R primer by Eurofins Genomics India Pvt. Ltd. Nucleotide sequences were translated using the ExPASy tools (http:// www.expasy.org/tools/dna.html) and appropriate reading frame for each gene was selected. Protein homology of translated products was determined using BLASTP (NCBI). Phylogenetic trees were constructed using MEGA 5 with the neighbor-joining method [48]. Figure 1 showed a detailed flow chart indicating overall methodology followed in the present study.

\section{Results}

Physicochemical characteristics of sludge samples

Physicochemical parameters of the sludge samples were summarized in Table 1 . All the three samples exhibited anoxic to strict anaerobic (DO: $0.01-0.66 \mathrm{mg} \mathrm{l}^{-1}$ ), reducing condition with low conductivity. The temperature of the two samples GR1 and DB2 obtained from sludge storage pits were close to the local daytime temperature of the regions $\left(35.2-35.6{ }^{\circ} \mathrm{C}\right)$, whereas GR3, collected from tank receiving the effluent from the refinery plant showed an elevated temperature of $44.9^{\circ} \mathrm{C}$. High TPH content with abundance of both aliphatic and aromatic hydrocarbons along with the presence of multiple heavy metals marked the characteristics of the three samples. GC-MS analysis revealed the presence of alkanes (C6-C40), cyclic- (C5, C6) and aromatic- (benzene, naphthalene, phenanthrene, etc.) hydrocarbons along with their substituents in the samples (Additional file 2: Table S2). Presence of several anions and heavy metals at varying concentrations was observed. Elevated sulfate concentration was detected in GR1 and DB2, while all three samples showed moderately high chloride concentrations with the highest amount in GR1. GR1 also showed relatively higher level of phosphate 


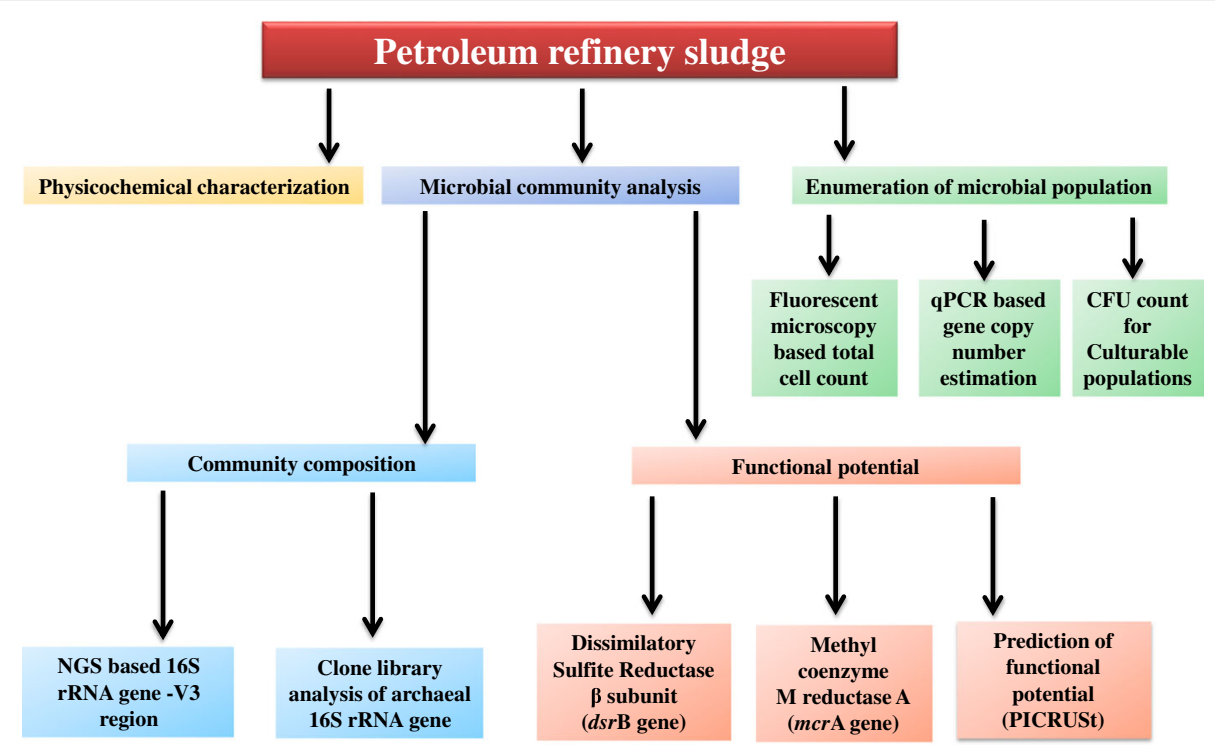

Fig. 1 Detailed flow chart indicating the overall methodology followed in the present study

compared to others. Nitrate and nitrite were detected at lower concentrations in all the samples, although the level of nitrate was up to 6 times higher than nitrite. Among the heavy metals, iron was most abundant, followed by chromium, zinc, nickel and copper. Arsenic and lead were present at relatively low concentrations. It was noted that GR1 and DB2 shared commonality with respect to multiple parameters including ORP, TPH, heavy metals and anions than that of GR3.

\section{Quantification of microbial cells}

Microbial abundance within the samples was quantified through total microscopic cell counts, enumeration of cultivable bacteria and real-time PCR (qPCR) based estimation of $16 \mathrm{~S}$ rRNA gene copy numbers (Table 1). Total

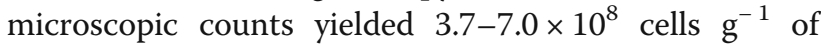
GR1 and DB2 samples. For GR3 cell counts could not be obtained due to strong interference from its very high TPH content. Aerobic and anaerobic cultivable bacterial counts were nearly equal in GR3 and DB2 samples $\left(\sim 10^{5}-10^{6} \mathrm{CFU} \mathrm{g}^{-1}\right)$, except in GR1 (anaerobic count was one order less). Microscopic and CFU data indicated that nearly $1 \%$ of the total cells present in these samples could be cultivable.

The concentration of metagenomic DNA extracted from the samples were in the range of 30-85 $\mathrm{ng} / \mu \mathrm{l}$. qPCR data indicated the presence of appreciable number of bacterial and archaeal 16S rRNA gene copies up to $2.35 \times$ $10^{10}$ and $2.5 \times 10^{8}$ per gram sample, respectively. Highest number of bacterial $16 \mathrm{~S}$ rRNA gene copy was observed in GR3 and maximum archaeal 16S rRNA gene was present in GR1 $\left(2.54 \times 10^{8}\right.$ copies $\left./ \mathrm{g}\right)$. Assuming an average of 4.60 copies of $16 \mathrm{~S}$ rRNA gene per bacterium and 1.71 per archaeal genome (https://rrndb.umms.med.umich.edu/), GR3 community was found to be hosted by $5.06 \times 10^{9}$ cells $\mathrm{g}^{-1}\left(5 \times 10^{9}\right.$ bacteria and $5.9 \times 10^{7}$ archaebacteria $)$, DB2 by $7.27 \times 10^{8}$ cells $g^{-1}\left(6.66 \times 10^{8}\right.$ bacteria and $6.12 \times$ $10^{7}$ archaebacteria) and GR1 by $1.1 \times 10^{9}$ cells g $^{-1}(9.49 \times$ $10^{8}$ bacteria and $1.49 \times 10^{8}$ archaebacteria). Estimated cell numbers obtained from microscopy and qPCR data corroborated well with each other, which ranged between $10^{8}$ and $10^{9}$ cells/g samples.

\section{Community level physiological profiling}

AWCD data indicated the rich physiological attributes of the refinery waste communities. Among the samples, DB2 and GR3 showed slightly more efficient utilization of the substrates provided in Biolog Eco Plate (Fig. 2a). Out of the six categories of substrates (amino acids, amines, carbohydrates, carboxylic acids, phenolics and polymers), amino acid was observed to be the most preferred in GR1 and GR3 while for DB2 it was carbohydrate followed by amines and amino acids (Fig. 2b, c, d). Overall, amino acids and amines were most and phenolics were least favored across the samples. Taking into consideration of the cell abundance, the observed metabolic richness highlighted the characteristic nature of these communities.

\section{Microbial community composition}

The total number of sequence reads per sample varied between 435,940-627,638 and a total number of 25,923 OTUs ( $>97 \%$ sequence similarity) could be obtained across the three samples (Table 2). Rarefaction analysis followed by Good's coverage indicated satisfactory sampling for all the three libraries (Additional file 3: Figure S1). The alpha 
Table 1 Physicochemical and microbiological parameters of oily sludge samples

\begin{tabular}{|c|c|c|c|}
\hline & GR1 & GR3 & DB2 \\
\hline \multicolumn{4}{|l|}{ Parameters } \\
\hline Site & Guwahati Refinery, IOCL & Guwahati Refinery, IOCL & Digboi Refinery, IOCL \\
\hline Geographical location & N $26^{\circ} 10.48^{\prime}$ E $091^{\circ} 48.00^{\prime}$ & N $26^{\circ} 10.48^{\prime}$ E $091^{\circ} 48.00^{\prime}$ & N $27^{\circ} 23.410^{\prime}$ E $095^{\circ} 36.665^{\prime}$ \\
\hline Nature of the sample & Oily sludge at waste disposal pit & Oily sludge at waste water lagoon & Oily sludge waste disposal pit \\
\hline \multicolumn{4}{|l|}{ Physicochemical parameters } \\
\hline Temperature $\left({ }^{\circ} \mathrm{C}\right)^{\mathrm{a}}$ & 35.2 & 44.9 & 35.6 \\
\hline $\mathrm{pH}^{\mathrm{a}}$ & 7.14 & 6.25 & 6.84 \\
\hline Dissolved Oxygen (mg/l) ${ }^{a}$ & 0.66 & 0.19 & 0.01 \\
\hline $\operatorname{ORP}(m V)^{a}$ & -157.7 & -30 & -182 \\
\hline Conductivity $(\mu \mathrm{S} / \mathrm{cm})^{\mathrm{a}}$ & 0.3 & 1.4 & 0 \\
\hline Moisture content $(\%, w / w)$ & 27.12 & 27.87 & 42.24 \\
\hline $\mathrm{TPH}(\mathrm{g} / \mathrm{kg})$ & 143.8 & 400 & 140.2 \\
\hline \multicolumn{4}{|l|}{ Hydrocarbons detected $(\%)^{b}$} \\
\hline Total Aliphatic Compounds & 60 & 71 & 75 \\
\hline Total Aromatics & 40 & 29 & 25 \\
\hline \multicolumn{4}{|l|}{ lons $(\mathrm{mg} / \mathrm{kg})^{\mathrm{c}}$} \\
\hline Nitrate & 18.24 & 7.87 & 13.63 \\
\hline Nitrite & 2.97 & $<2.0$ & 9.07 \\
\hline Chloride & 704.00 & 469.85 & 469.85 \\
\hline Sulfate & 6109 & 222 & 6621 \\
\hline Phosphate & 537.6 & 17 & 167 \\
\hline Ammonium & 3.24 & 3.49 & 3920 \\
\hline \multicolumn{4}{|l|}{ Metals $(\mathrm{mg} / \mathrm{kg})^{\mathrm{d}}$} \\
\hline Sodium & 3.13 & 2.23 & 3.56 \\
\hline Calcium & 49.51 & 30.50 & 78.25 \\
\hline Chromium & 45.39 & 8.07 & 48.38 \\
\hline Iron & 150.47 & 302.97 & 101.13 \\
\hline Cobalt & 1.34 & 2.39 & 2.53 \\
\hline Nickel & 34.93 & 7.11 & 38.72 \\
\hline Copper & 12.92 & 2.39 & 12.89 \\
\hline Zinc & 34.70 & 131 & 68.14 \\
\hline Arsenic & 2.24 & 1.27 & 2.22 \\
\hline Cadmium & 0.06 & 0.16 & 0.05 \\
\hline Lead & 2.68 & 4.02 & 2.62 \\
\hline \multicolumn{4}{|l|}{ Microbial Counts } \\
\hline $\begin{array}{l}\text { Total microbial counts using } \\
\text { fluorescence microscopy } \\
\text { (cells/g of sample) }\end{array}$ & $(7.01 \pm 0.87) \times 10^{8}$ & ND & $(3.73 \pm 0.68) \times 10^{8}$ \\
\hline \multicolumn{4}{|l|}{ CFU/g of samples } \\
\hline MSM & $(1.65 \pm 0.78) \times 10^{6}$ & $0.2 \times 10^{6}$ & $(5 \pm 0.14) \times 10^{6}$ \\
\hline R2A & $(8 \pm 1.41) \times 10^{5}$ & $(6.5 \pm 1.5) \times 10^{6}$ & $(7.35 \pm 0.21) \times 10^{6}$ \\
\hline Anaerobic agar & $(3 \pm 0.14) \times 10^{5}$ & $(2 \pm 0.7) \times 10^{6}$ & $(1.23 \pm 0.14) \times 10^{6}$ \\
\hline Gene of interest & Copy no./g sample & & \\
\hline Bacteria (16S rRNA gene) & $4.46 \times 10^{9}$ & $2.35 \times 10^{10}$ & $3.13 \times 10^{9}$ \\
\hline Archaea (16S rRNA gene) & $2.54 \times 10^{8}$ & $1.01 \times 10^{8}$ & $1.04 \times 10^{8}$ \\
\hline
\end{tabular}


Table 1 Physicochemical and microbiological parameters of oily sludge samples (Continued)

\begin{tabular}{llll}
\hline & GR1 & GR3 & DB2 \\
\hline mcrA & $1.75 \times 10^{6}$ & $2.29 \times 10^{6}$ & $1.66 \times 10^{6}$ \\
$d s r B$ & $2.22 \times 10^{8}$ & $4.02 \times 10^{7}$ & $3.48 \times 10^{8}$
\end{tabular}

${ }^{a}$ Measured during sample collection using Orion star series multiparameter (Thermo Orion meter Beverly, USA)

${ }^{\mathrm{b}}$ Analysed and Identified by gas chromatograph coupled with mass spectrometer (GC-MS) (Perkin Elmer, USA)

'Estimated by spectrophotometric and titrimetric methods of American Public Health Association

${ }^{\mathrm{d}}$ Estimated by ICP-MS (inductively coupled mass spectrometery) (Varian Palo Alto CA USA) and /or atomic absorption spectroscopy (AAS) (Perkin Elmer MA, USA) ND, Not detected

diversity indicators, viz., Chao1, equitability, Shannon's and Simpson's indices, were summarized and compared with other similar microbial habitats (Table 2 and Tables S3). Shannon diversity index for GR1 and DB2 were slightly higher than GR3, but all values were within the range as reported from several other petroleum production/injection wells, contaminated soil, etc. in recent years (Additional file 4: Table S3). At 97\% similarity level, a minor fraction of the total OTUs (4.9\%) was shared among the three samples, but accounted for $\geq 84 \%$ of the total sequences and leaving considerable fractions (16-41\% of the OTUs) unique to each sample (Additional file 5: Figure S2). At taxonomic level, over $68 \%$ (41) phyla, $49 \%$ (135) families and 35\% (140) genera were found to be common in the samples
(Additional file 5: Figure S2). Highest numbers of taxa were found to be shared between DB2 and GR1 at both family and genus levels.

\section{Beta diversity}

Distribution of bacterial phyla across the samples was delineated based on their relative abundance (Fig. $3 \mathrm{a}$ and Additional file 6: Figure S3). Members of Proteobacteria, Chloroflexi, Firmicutes and candidate division OP8 constituted major proportions (69-83\%) in all the three communities. Thermotogae, Actinobacteria, Spirochaetes, Caldiserica, Nitrospirae, Bacteroidetes, candidate divisions TM6 and OD1, Synergistetes, Elusimicrobia, candidate division TM7 and Acidobacteria were present as less abundant populations. Chlorobi, candidate division

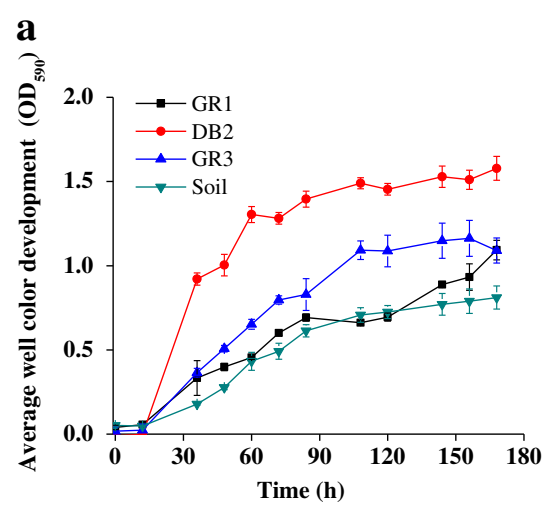

b
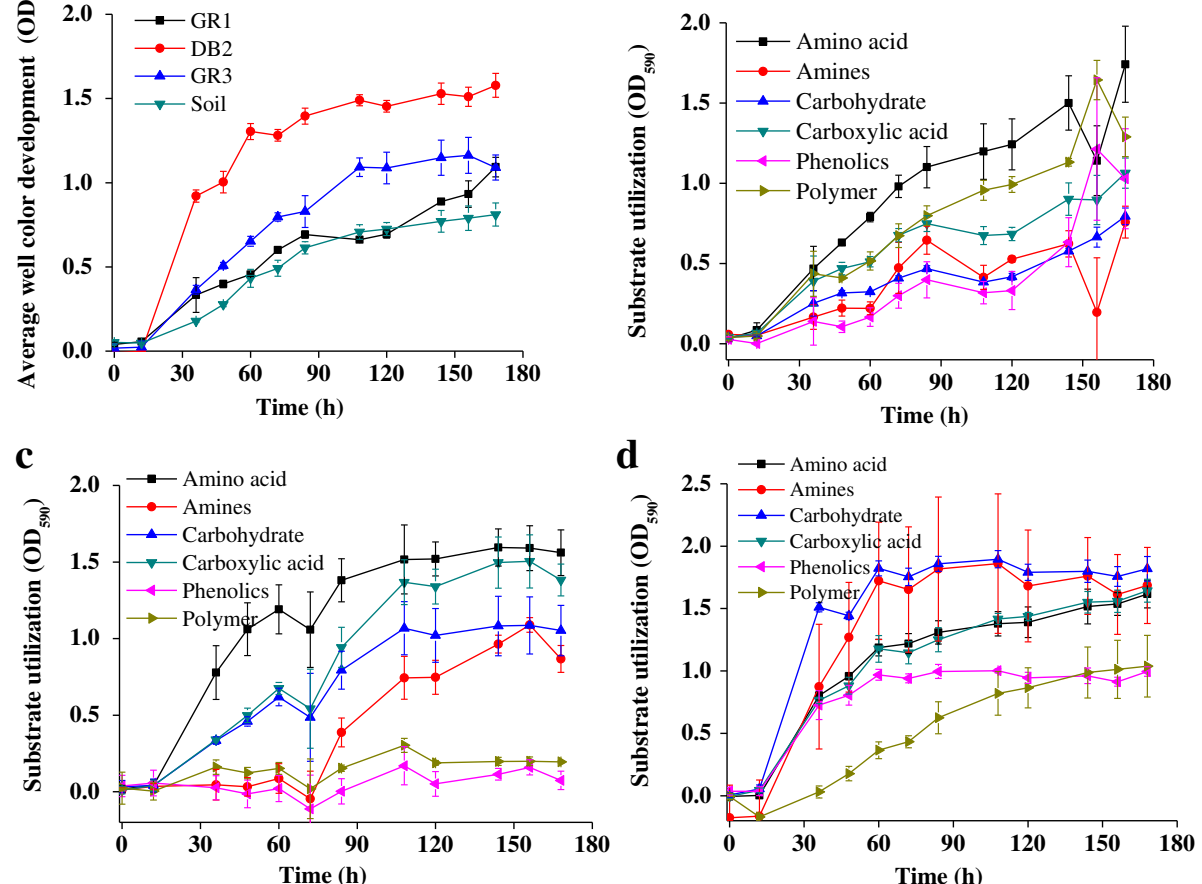

Fig. 2 Community level physiological profiles of GR1, DB2 and GR3 sludge samples. Average well color development (AWCD) was plotted with time for the samples along with a non-polluted soil (Soil) (a). Color development was monitored till $180 \mathrm{~h}$. Error bars represent the standard error of mean $(n=3)$. Utilization of seven categories of substrates by three sludge samples over time, GR1 (b), GR3 (c) and DB2 (d) 
OP11, Deferribacteres, Fibrobacteres, Cyanobacteria, Armantimonadetes, candidate division TA06, SR1, etc. were found as minor groups indiscriminately.

Proteobacteria was the single most abundant phylum in GR3 (78\%) and also the second most abundant group in DB2 (19\%), while it contributed only $6.5 \%$ in GR1. Members of Delta, Beta and Gamma sub-divisions constituted nearly 99\% of Proteobacteria in GR3 (Fig. 3b). GR1 and DB2 exhibited a near similar composition with Firmicutes, Chloroflexi, OP8, Thermotogae, Actinobacteria, Caldiserica, Nitrospirae, Bacteroidetes and Alphaproteobacteria as the major contributors of respective communities (Fig. 3a). Anaerolinae, Dehalococcoidetes, Ellin6529, Thermomicrobia etc., of phylum Chloroflexi and Clostridia of Firmicutes constituted major bacterial groups in both GR1 and DB2 (Fig. 3b). Thermotogae (of phylum Thermotogae) was a dominant (13\%) group in GR1, but also present at moderate abundance in DB2 and GR3 (4.3 and $2.5 \%$, respectively).

Table 2 Read and OTU distribution of the samples obtained through next generation sequencing (Illumina), diversity indices (calculated using QIIME workflow) and taxonomical distribution

\begin{tabular}{|c|c|c|c|}
\hline & GR1 & GR3 & DB2 \\
\hline \multicolumn{4}{|l|}{ Parameters } \\
\hline Number of reads & 627,638 & 435,940 & 472,180 \\
\hline OTUs (97\% identity) & 7837 & 12,774 & 10,617 \\
\hline Estimated total OTUs (Chao1) & $15,448.14$ & $32,314.94$ & $25,135.21$ \\
\hline Shannon diversity index & 6.148 & 4.443 & 6.369 \\
\hline Simpson index & 0.9452 & 0.7081 & 0.95 \\
\hline Equitability & 0.475 & 0.326 & 0.476 \\
\hline Goods coverage & 0.9933 & 0.9819 & 0.9863 \\
\hline Archaeal taxa (\% Reads) & 0.03 & 0.0002 & 0.02 \\
\hline Bacterial taxa (\% Reads) & 95.41 & 99.14 & 97.07 \\
\hline Unclassified (\% Reads) & 4.56 & 0.86 & 2.91 \\
\hline \multicolumn{4}{|l|}{ Number of Archeal taxa detected } \\
\hline Phylum & 2 & 1 & 2 \\
\hline Class & 3 & 1 & 5 \\
\hline Family & 2 & 1 & 3 \\
\hline Genus & 2 & 1 & 3 \\
\hline Genus $^{e}$ & 2 & 2 & 2 \\
\hline Genus common in 3 samples & 1 & & \\
\hline \multicolumn{4}{|l|}{ Number of Bacterial taxa detected } \\
\hline Phylum & 49 & 46 & 49 \\
\hline Class & 118 & 96 & 116 \\
\hline Family & 213 & 186 & 215 \\
\hline Genus & 280 & 244 & 285 \\
\hline Genus common in 3 samples & 139 & & \\
\hline
\end{tabular}

Detected through clone library
Taxonomic distribution at lower levels showed that although a considerable proportion (97\%) of GR3 reads could be assigned to family level (compared to 65-69\% in GR1 and DB2), genus level assignment of was achieved only for $35 \%$ of GR3 reads (49-57\% in GR1 and DB2). A total of 418 genera were detected and out of these 140 were common across the three samples. Figure 4 represented the relative abundance of major families across the samples as a semi-quantitative heat map (represented in the text as families (genus); families having $\geq 0.2 \%$ cumulative abundance was considered). WPGMA of these major families present in all three samples showed presence of three broad, yet distinct clades suggesting the correlation among these taxa. Syntrophaceae (Syntrophus) of Deltaproteobacteria was found to be the single most dominant group (>60\% abundance) in GR3, correlated with two other major groups of GR3 namely Spirochaetaceae (Treponema) (12\%) and Rhodocyclaceae (Azovibrio, Thauera, Petrobacter and Dechloromonas) (10\%). Thermodesulfobiaceae (Coprothermobacter and Thermodesulfobium) of Firmicutes, Anaerolineaceae (T78 and Anerolinea) of Chloroflexi and unclassified OP8 members represented the most abundant populations in GR1 and DB2. In contrast to GR3 and DB2, GR1 community harbored considerable proportion (15\%) of Thermotogaceae (Fervidobacterium) a member of Thermotogae, Sphingomonadaceae (Kaistobacter), Acetobacteriaceae (Acidocella, Acidisoma, Acidiphilum, Acetobacter, etc) and Hyphomicrobiaceae (Hyphomicrobium, Rhodoplanes, Parvibacculum) were detected in both DB2 and GR1 with moderate-low abundance (5-0.8\%). Noticeably, members of Xanthomonadaceae (Pseudodoxanthomonas, Stenotrophomonas, etc), Commamonadaceae (Thiomonas, Acidovorax, Hydrogenophaga, etc) and Syntrophobactereaceae (Syntrophobacter, Desulfoglaeba, Desulforhabdus, etc) were present with relatively higher abundance in GR3. There were a number of other families detected with relatively lower abundance in both GR1 and DB2 samples. The family (genus) level community profiles indicated distinctiveness in GR3 leaving DB2 and GR1 more closely related to each other.

Abundance of genera (cumulative abundance $\geq 0.1 \%$ ) within the test sludge samples were depicted in Fig. 5. GR1 sample showed presence of Coprothermobacter (14.99\%), Fervidobacterium (12.68\%), T78 (9.53\%) as abundant groups. Anaerostipes (1.45\%), Thermodesulfovibrio (1.07\%), Anaerolinea (1.05\%), etc., were also found. Several other taxa (e.g. Tissierella_Soehngenia, Mycobacterium, Hyphomicrobium, Clostridium, WCHB1-05, Gordonia, Azovibrio, Paracoccus, Novosphingobium, etc.) with minor abundance were present in GR1. In GR3 sample the major taxa found were: Treponema (11.87\%), Azovibrio (9.3\%), Syntrophus (6.57\%), Coprothermobacter (2.88\%), and Fervidobacterium (2.55\%). Presence of Sytrophobacter (0.27\%), Geobacter $(0.16 \%)$, etc., was noted. The sample from Digboi refinery 


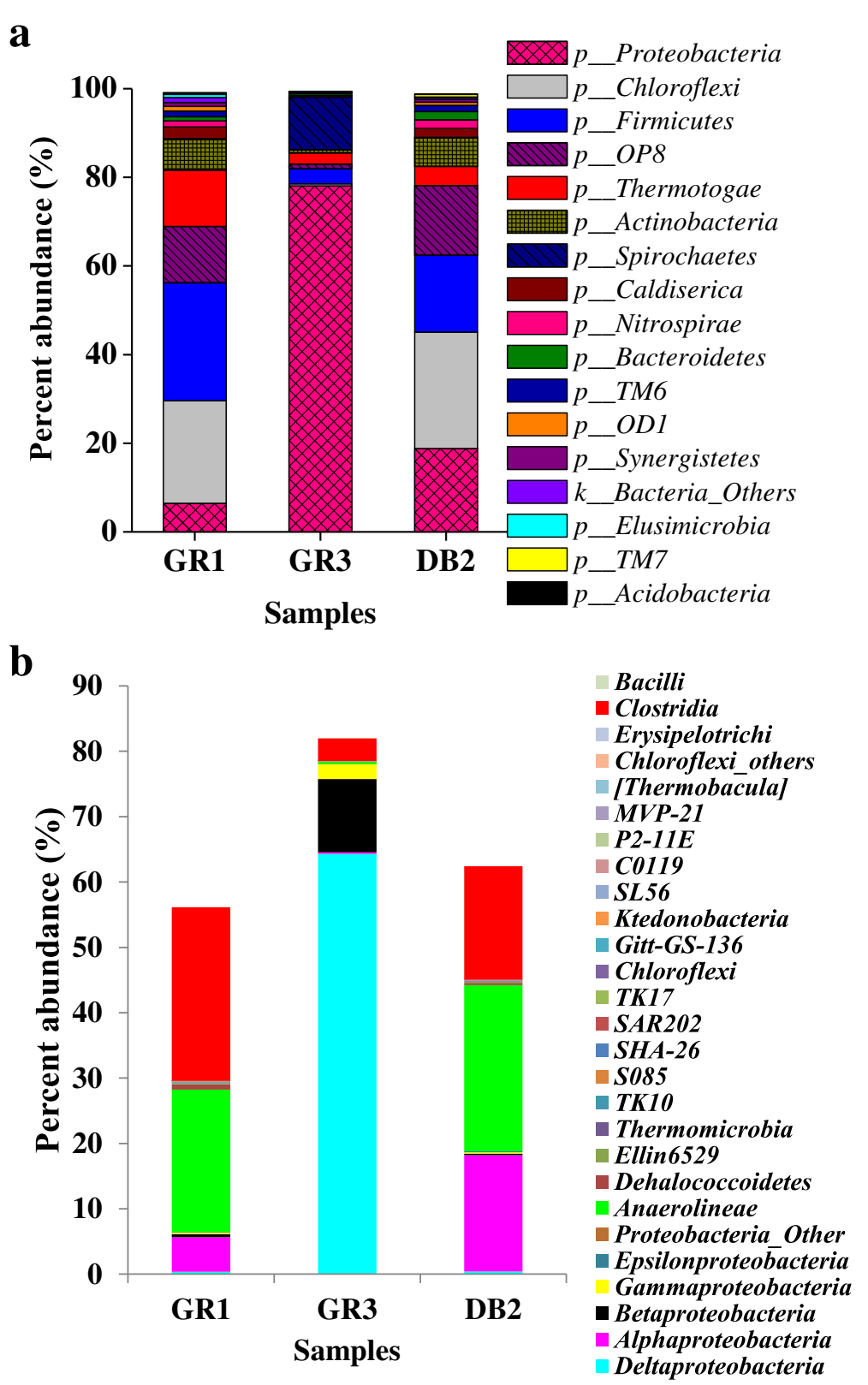

Fig. 3 Composition of three microbial communities at phylum (a) and class (b) levels. Phyla with cumulative abundance $\geq 0.5 \%$ (across the three samples) were considered. Class level distribution was plotted for three major phyla Proteobacteia, Chlroflexi and Firmicutes

(DB2) showed a near similar composition to that of GR1 recovered from Guwahati refinery. Members of T78 (14.18\%), Coprothermobacter (12.51\%), Kaistobacter (4.71\%), Fervidobacterium (4.31\%), Xanthobacter (3.06\%), Longilinea (2.36\%), Mycobacterium (1.76\%), Anaerostipes (1.45\%), Tissierella_Soehngenia (1.35\%), Clostridium (1.22\%), etc. were detected in DB2. Many other genera like Acetobacterium, Dietzia, Moorela, Methanobacterium, Methylosinus, Methylobacterium, Methanosaeta, etc. were present as less abundant members (cumulative abundance <0.1\%) across the samples (Additional file 7: Figure S4).

\section{Analysis of abundant OTUs}

Correlation and phylogenetic lineages of de novo OTUs abundant across the three samples were analyzed. Top fifty abundant OTUs (covering 76-84\% of total quality reads) were selected and Pearson correlation among their individual abundances was calculated together with UPGMA (Unweighted Pair Group Method with Arithmetic Mean) (Fig. 6). Correlation pattern among these OTUs exhibited four distinct clusters. Phylogenetic lineages of OTUs from each of these four clusters were determined (Additional files 8, 9, 10, 11: Figures S5-S8). The 


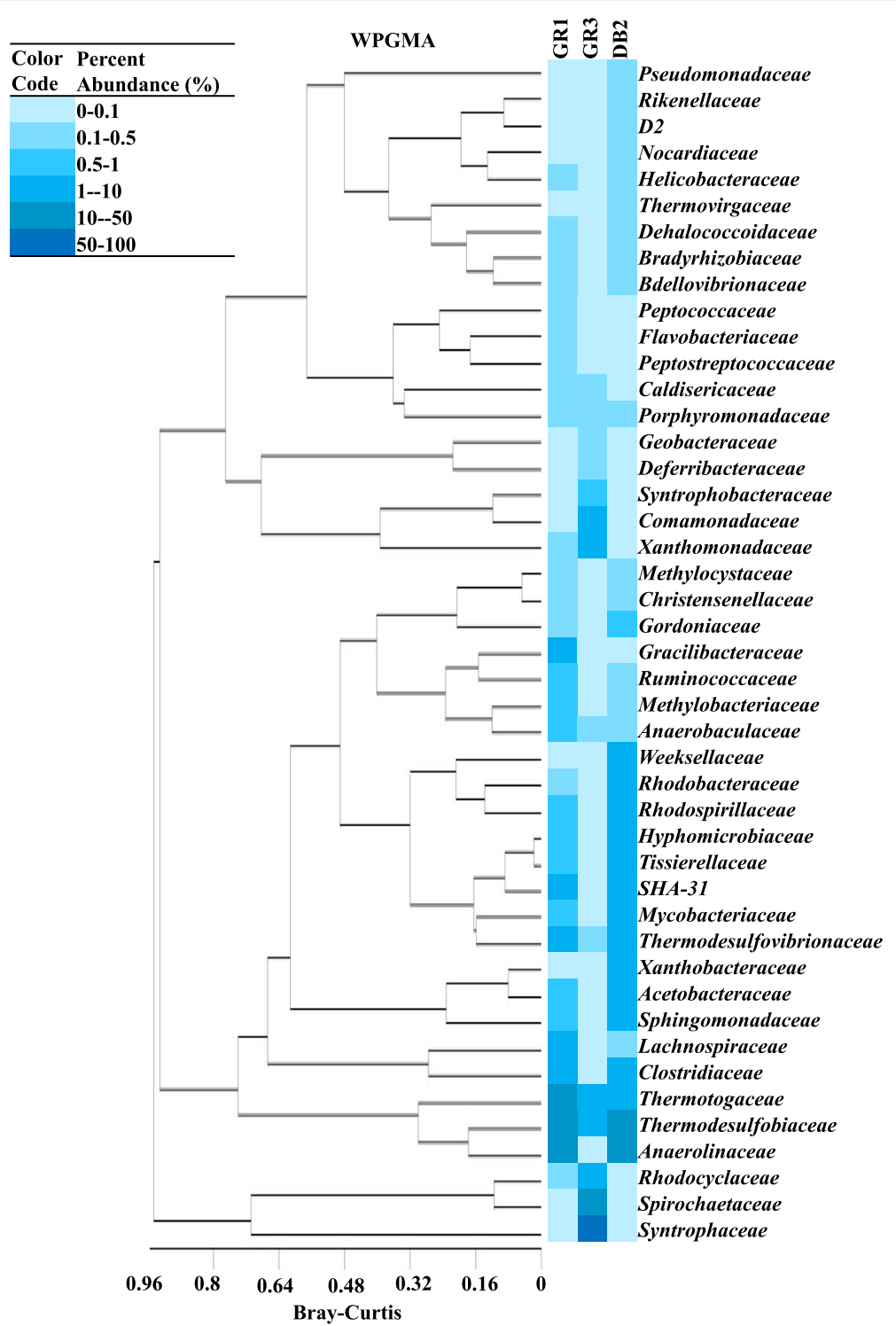

Fig. 4 Heat map indicating the relative abundance of major families with cumulative abundance of $>0.2 \%$ on the basis of WPGMA (Weighted Pair Group Method with Arithmetic Mean)

first clade comprised of 21 OTUs representing 53\%, 34\% and $4 \%$ of reads from GR1, DB2 and GR3 respectively showing their lineage with anaerobic, sulfate-reducing organisms having a syntrophic association with methanogens. Taxonomically, these OTUs were mostly affiliated to members of Firmicutes (Coprothermobacter, Clostridiales members) and Chloroflexi (Anaerolineae) (Additional file 8: Figure S5). The second clade of 12 OTUs covered 26\%, $19 \%$ and $2 \%$ of total reads from DB2, GR1 and GR3, respectively. OTUs of this clade were phylogenetically related to anaerobic, thermophilic, sulfate-reducing Thermodesulfovibrio, Anaerolineae, OP8 and a few members of Actinobacteria (Additional file 9: Figure S6).The third clade comprised of 11 OTUs $(24 \%, 2 \%$ and $0.04 \%$ of
DB2, GR1 and GR3 respectively) that showed lineages with mostly sulfate reducing, $\mathrm{N}_{2}$ fixing and syntrophic bacteria from hydrocarbon contaminated sites (Additional file 10: Figure S7). The last clade comprised of 6 OTUs $(73.37 \%, 0.98 \%$ and $0.76 \%$ of GR3, GR1 and DB2, respectively) which were phylogenetically related to organisms capable of $\mathrm{N}_{2}$ fixation, sulfate-reduction and/or syntrophic metabolism (Additional file 11: Figure S8).

\section{Comparison of microbial communities of different petroleum hydrocarbon contaminated environments} Microbial communities of the test samples were compared with that of fifteen other previously reported petroleum hydrocarbon contaminated environments 


\begin{tabular}{|c|c|c|c|c|}
\hline Genus & GR1 GR3 DB2 Genus & GR1 GR3DB2 & $\overline{\text { Color }}$ & Percent \\
\hline Coprothermobacter & Bdellovibrio & & Code & abundance \\
\hline$T 78$ & Paracoccus & & & $15-10$ \\
\hline Fervidobacterium & Acidocella & & & $9.9-5$ \\
\hline Treponema & DCE29 & & & $4.9-3$ \\
\hline Azovibrio & Bosea & & & $2.9-1$ \\
\hline Syntrophus & Proteiniclasticum & & & $0.99-0.1$ \\
\hline Kaistobacter & $S H D-231$ & & & $0.09-0.01$ \\
\hline Xanthobacter & Syntrophobacter & & & $0.009-0.001$ \\
\hline Thermodesulfovibrio & Azospirillum & & & 0 \\
\hline Longilinea & Anaerobaculum & & & \\
\hline Mycobacterium & Blvii28 & & & \\
\hline Tissierella_Soehngenia & Rhodococcus & & & \\
\hline Anaerolinea & Novosphingobium & & & \\
\hline Thermoanaerobacterium & Geobacter & & & \\
\hline Anaerostipes & Pseudomonas & & & \\
\hline Hyphomicrobium & Anaerovorax & & & \\
\hline WCHB1-05 & Agrobacterium & & & \\
\hline Chryseobacterium & E6 & & & \\
\hline Gordonia & Paludibacter & & & \\
\hline Clostridium & Ruminococcus & & & \\
\hline Rhodobacter & Butyrivibrio & & & \\
\hline C1_B004 & Microbacterium & & & \\
\hline Rhodoplanes & Deferribacter & & & \\
\hline
\end{tabular}

Fig. 5 Heat map indicating the relative abundance of major genera with cumulative abundance of $>0.1 \%$

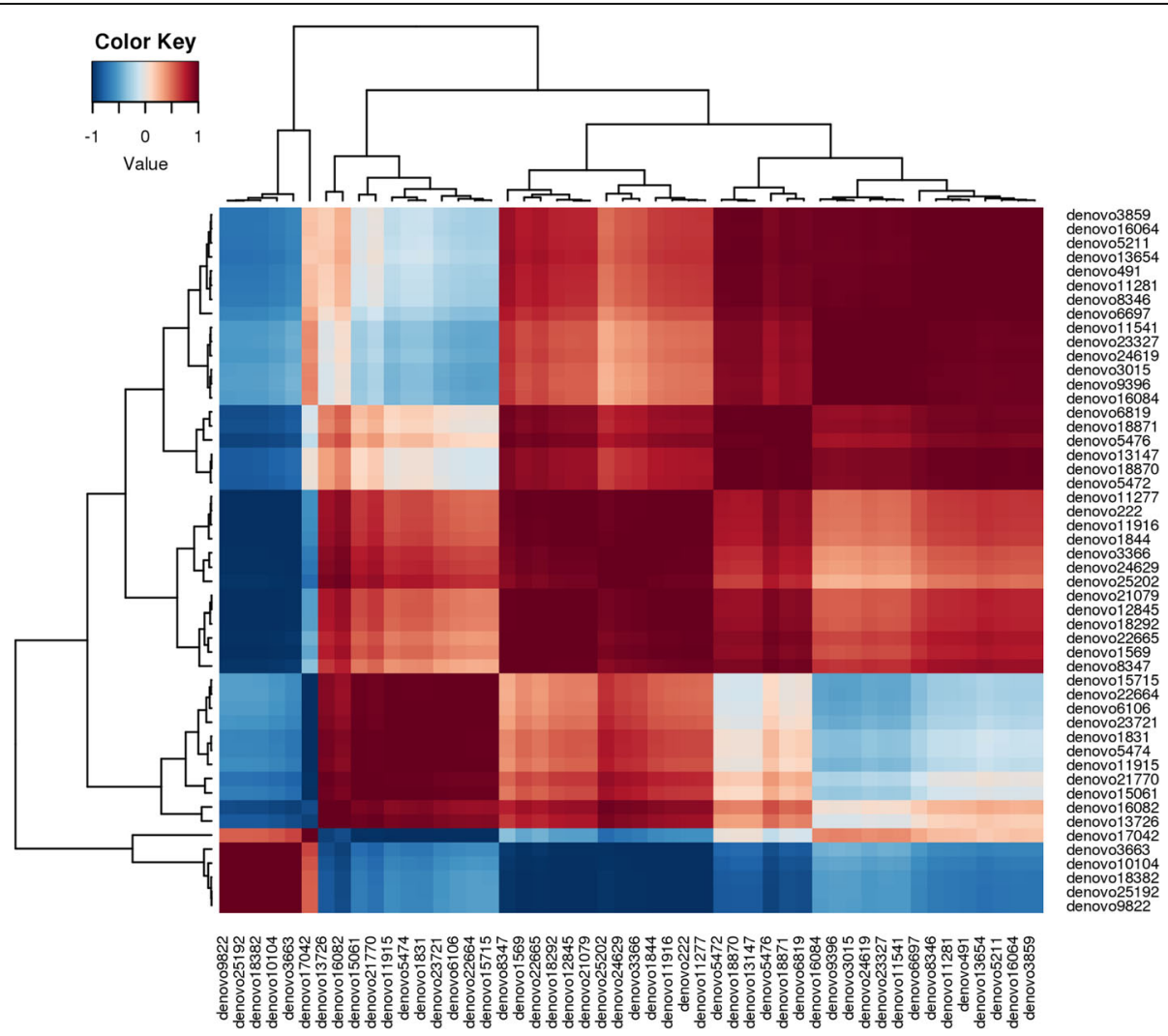

Fig. 6 Heat map and UPGMA indicating the Pearson co-efficient of top 50 most abundant OTUs across the samples 
(Additional file 12: Table S4). Relative abundance of the major phyla present in each sample was plotted as a heat map (Fig. 7). Proteobacteria was found as an omnipresent phylum with more than $50 \%$ relative abundance in seven out of total eighteen samples. Average abundance of this phylum was $36 \%$. Actinobacteria, Firmicutes, Bacteriodetes and Chloroflexi were also found to be universally occurring taxa with varying abundance. Average abundance of these four taxa was in the range of 4-19\%. Euryarchaeota was found to be a prevalent archeal taxon in several samples including the test ones. The UPGMA based on Euclidean similarity indices showed three distinct clades among the samples. The first clade was comprised of refuelling station samples (B3_RS and B4_RS) and the test refinery sludge samples DB2 and GR1. Second clade was comprised of oil exploration site samples (XJ, DQ and SL), oil contaminated sediments (A3, B3 and C3), fuel spill Arctic soil (JP-8) and tailing ponds sample (SU3) along with test refinery sludge GR3. Finally, the third clade was comprised of Hubai oil field samples (HB) with naturally attenuated (NA) and bioremediated soil (BT) contaminated with oil. GR1 and DB2 samples were closely associated within the dendogram along with the refuelling station samples because of relatively higher Firmicutes (average around 20.4\%) and comparatively lower abundance of Proteobacteria (average around 12\%). GR3 was grouped with oil contaminated soil and sediment due to high abundance of Proteobacteria (average around 57\%).

\section{Analysis of archaeal populations}

The composition of archaeal populations was delineated by analyzing archaeal $16 \mathrm{~S}$ rRNA gene clone libraries. Total 332 clones from three samples were analyzed. Sequence analysis of all major and several minor $(<1 \%$ abundance) OTUs (ARDRA phylotypes) revealed the
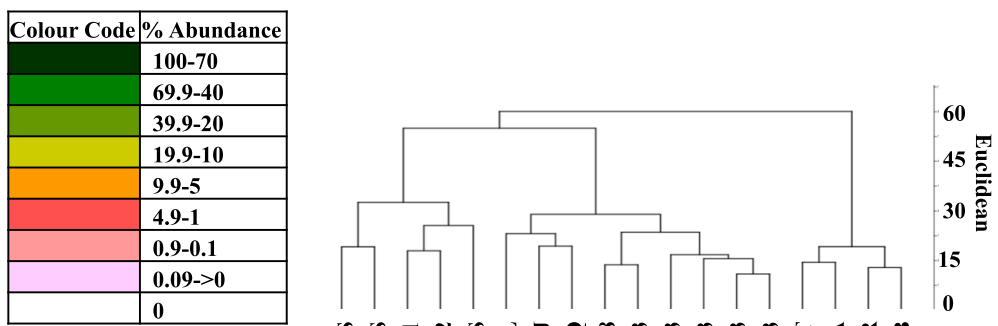

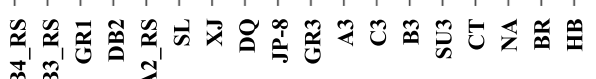

Phyla $\vec{\oplus} \tilde{\theta}$

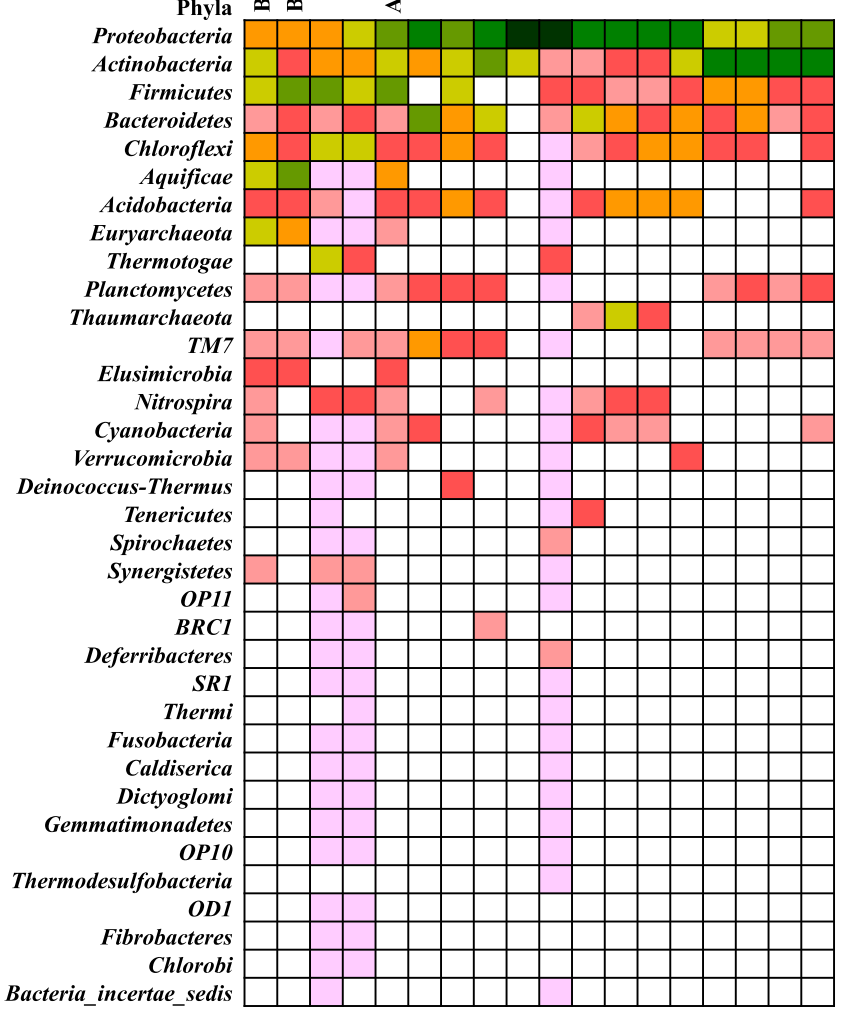

Fig. 7 Comparison of microbial communities of different petroleum hydrocarbon contaminated environments on the basis of their phylum distribution 

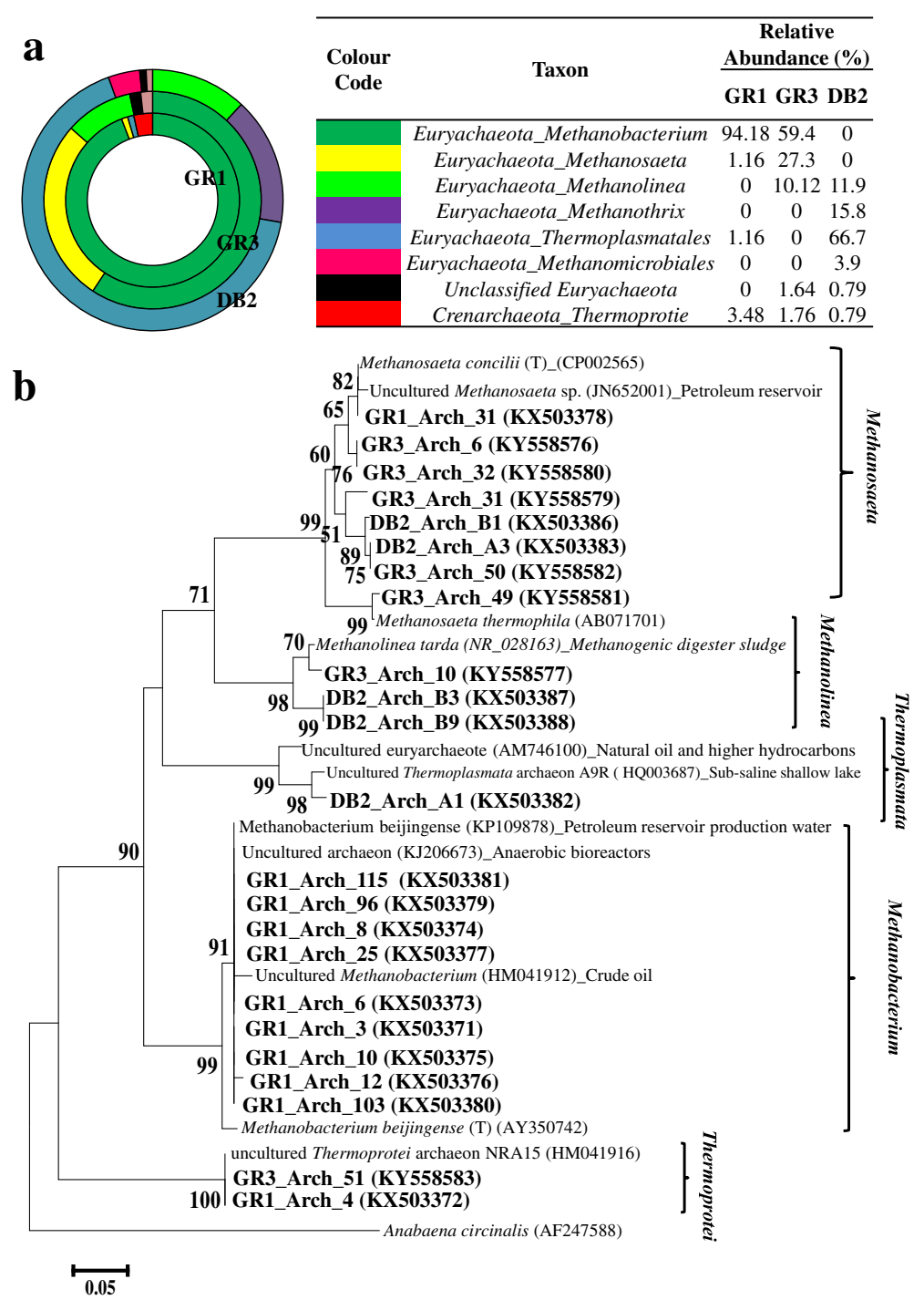

Fig. 8 Archaeal distribution and phylogenetic tree of archaeal 16S rRNA gene sequences retrieved from the samples. Distribution of archaebacterial taxa in GR1, GR3 and DB2 (a) using clone library analysis. Phylogentic tree was constructed using the neighbour joining method incorporating Jukes-Cantor distance corrections (b). Sequence of Anabaena circinalis was used as the out-group. One thousand bootstrap analyses were conducted and bootstrap values $>50 \%$ were indicated at the nodes. Scale bar $=0.05$ change per nucleotide position

dominance of the phylum Euryarchaeota (Fig. 8a), which was mostly represented by families Methanobacteriaceae (genus Methanobacterium) in GR1 and GR3, Methanosaetecae (Methanosaeta) in GR3, Methanoregulaceae (Methanolinea) in DB2 and GR3 and class Thermoplasmata predominantly in DB2. Phylum Crenarchaeota, present as the relatively minor population in all three samples, was represented by unclassified Thermoprotei members.

Phylogenetic lineages of archaeal sequences were studied (Fig. 8b). Sequences affiliated to Methanobacterium were closely related to methanogenic Methanobacterium beijingense type strain 8-2; isolated earlier from the anaerobic digester [49]. Members of Methanosaeta showed their close relatedness with $M$. concilii, which is a "specialist in acetoclastic methanogenesis" [50]. A single OTU from GR3 also showed affiliation to M. thermophilia [51]. A few OTUs from DB2 and GR3 were distantly related to the Methanolinea clade but showed their closeness with Methanolinea tarda, a novel methane producing strain originally obtained from a mesophilic methanogenic sludge digesting municipal sewage sludge [52]. Clones representing the class Thermoprotei showed phylogenetic relatedness with uncultured Thermoprotei archaeon NRA15 reported earlier from microbial communities associated with crude oil, large insoluble particles and formation water components of the reservoir fluid from a non-flooded high-temperature petroleum reservoir [15]. 


\section{PICRUSt analysis}

PICRUSt analysis was done to predict the putative metabolic properties of microbial communities in the samples. For better insight, we have split the taxonomic assignment data into archaeal and bacterial reads separately. The NSTI for the bacterial library in all three samples varied from 0.18 to 0.11 in GR1, DB2 and GR3 respectively. Broad classes of KEGG pathways predicted in each of the samples are presented in Fig. 9a. Genes related to metabolic activities accounted for almost $46-52 \%$ of entire genetic repertoire in GR3, GR1 and DB2 metagenome.

The most abundant group of metabolism-related genes in three metagenomes were those involved in carbohydrate- ( $20 \%$ to $22 \%$ of all the genes involved in metabolism) followed by amino acid- (20.3\% to $20.6 \%)$ and energy- metabolism (12.09\% to $13.03 \%$ ) (Fig. 9b). The predicted bacterial metagenomes of GR3 differed mostly from the rest two with respect to different sub-categories of gene system for metabolism. Gene prediction on carbohydrate metabolism revealed a relatively higher degree of allocation of genes related to butanoate, glyoxylate and dicarboxylate metabolism in GR3 compared to the other two samples (Additional file 13: Table S5), while the genes allocated for glycolysis/gluconeogenesis, TCA cycle, propionate and pyruvate metabolism was found to be less in GR3 than GR1 and DB2. With respect to amino acid metabolism, amino acid related enzymes (12.53\% to $14.64 \%$ of all amino acid metabolism genes), followed by genes encoding arginine and proline metabolism were abundant (Additional file 13: Table S5). The latter, along with the genes for cysteine and methionine metabolism were less abundant in GR3. With respect to energy metabolism, oxidative phosphorylation-related genes were highly abundant in GR1 and DB2 followed by genes for $\mathrm{CO}_{2}$ fixation in prokaryotes. However, the latter system was most abundant in GR3. Genes for methane and nitrogen metabolism were present in all three samples with considerable abundance (with slightly higher values in GR3).

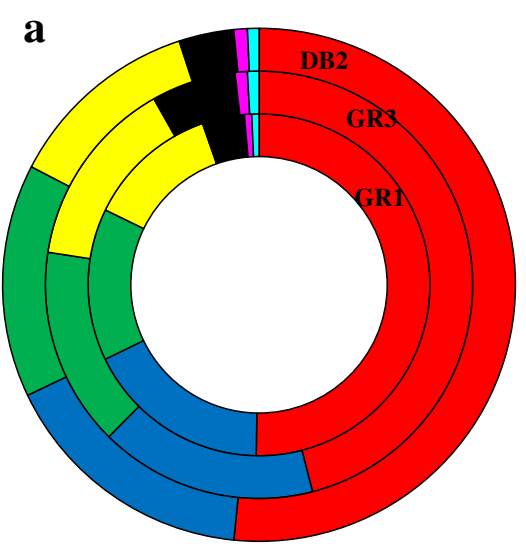

$\square$ Metabolism

$\square$ Genetic Information Processing

$\square$ Environmental Information

Processing

$\square$ Unclassified

- Cellular Processes

$\square$ Human Diseases

$\square$ Organismal Systems

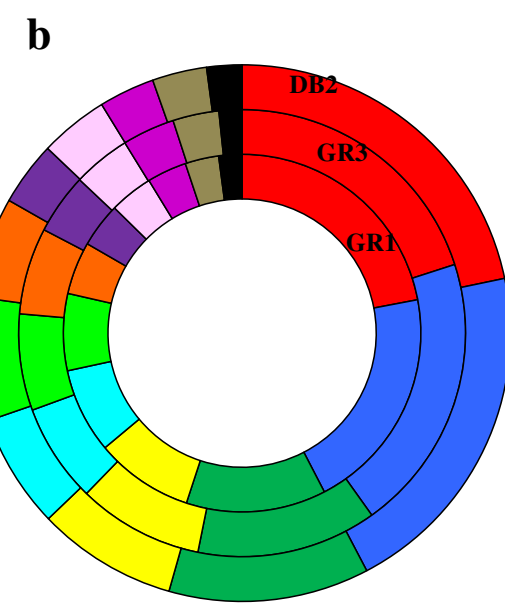

口 Carbohydrate Metabolism

$\square$ Amino Acid Metabolism

$\square$ Energy Metabolism

$\square$ Metabolism of Cofactors and

Vitamins

$\square$ Nucleotide Metabolism

$\square$ Lipid Metabolism

$\square$ Xenobiotics Biodegradation and

Metabolism

$\square$ Glycan Biosynthesis and Metabolism

$\square$ Metabolism of Terpenoids and

Polyketides

$\square$ Enzyme Families

$\square$ Metabolism of Other Amino Acids

- Biosynthesis of Other Secondary Metabolites

Fig. 9 PICRUSt based analysis of functional potential of three communities. Overall distribution of the functional inventory in GR1, GR3 and DB2 (a). Distribution of genes involved in metabolism within the samples (b) 
Interestingly, genes related to photosynthesis were relatively more frequent in GR1 and DB2 rather than GR3. This fact about photosynthetic ability of GR1 and DB2 communities corroborated very well with abundant anoxic photosynthetic green non-sulfur bacteria like T78 and WCHB1-05 in these two samples. Among xenobiotic degradation, genes related to xylene, nitrotoluene, naphthalene and benzoate degradation were observed more in GR3 as compared to GR1 and DB2. Certain xenobiotic degradation genes like, toluene, flurobenzoate, styrene, atrazine, bisphenol, chloroalkene, etc. were observed more abundantly in DB2. Among lipid metabolizing genes, lipid biosynthetic proteins were on the top of the list. Interestingly, genes related to fatty acid biosynthesis were more in GR1 and DB2 than GR3 while fatty acid metabolism was highest in GR3 and lowest in GR1. Among the genetic systems for environmental information process, genes related to membrane transport (including transporter, $\mathrm{ABC}$ transporters and secretion system) were most abundant followed by those involved in signal transduction (majorly two-component systems). Genes under the genetic information processing category were mostly related to DNA repair and recombination proteins, ribosomes, aminoacyl tRNA biosynthesis, transcription factors etc., involved in several processes of replication, repair, translation, transcription, followed by sorting and degradation.

\section{Analysis of functional genes}

Quantitative real-time PCR was used to determine the abundance of $m c r \mathrm{~A}$ and $d s r \mathrm{~B}$ genes. These two genes were targeted considering the potential role of methane metabolizing and sulfate-reducing populations within the studied communities. Nearly equal distribution $\left(\sim 10^{6}\right.$ gene copies $\mathrm{g}^{-1}$ sample) of the $\mathrm{mcr}$ A gene in all the three samples was noted. In contrast, abundance of the $d s r \mathrm{~B}$ gene was found to be relatively higher in GR1 and DB2 ( $10^{8}$ gene copies $\mathrm{g}^{-1}$ sample) compared to GR3 $\left(10^{7}\right.$ gene copies $\mathrm{g}^{-1}$ sample) (Table 1). Phylogenetic analysis based on derived amino acid sequences of $m c r A$ gene indicated a close relatedness to Methanobacterium beijingense and uncultured Methanobacteriales retrieved from petroleum reservoir or production water, syntrophic organisms capable of degrading butyrate and propionate, obligate hydrogenotrophic methanogen Methanocella and acetoclastic methanogen Methanosaeta (Fig. 10a). Abundance of Methanobacterium in the sludge samples were also reported from clone library of archaeal 16S rRNA gene. Phylogenetic analysis of $d s r \mathrm{~B}$ gene revealed the lineages of $d s r \mathrm{~B}$ genes with two major taxonomic domains of the communities, namely the Deltaproteobacteria and Firmicutes along with Nitrospirae members. Particularly, the sequences showed close affiliations to $d s r \mathrm{~B}$ sequences from Desulfobacca, Syntrophobacter, Desulfoglaeba, Desulfomonile and Desulfobulbus of Deltaproteobacteria;
Desulfotomaculum, Moorella and Peptococcaceae of Firmicutes and Nitrospirae (Fig. 10b).

\section{Discussion}

The present study elucidated microbial ecology of three hydrocarbon enriched refinery wastes providing better insights into the community structure, metabolic potential of major populations and the complex interrelations among the populations. Strong reducing condition coupled with lack of disolved oxygen, adequate moisture, nitrogen and phosphorus levels of the samples corroborated well with the characteristic nature of hydrocarbon-rich, anoxic oily sludge and hydrocarbon resource environment $[10,30,42,53]$. According to the Peters-Moldowan scale on quantitative estimation of the mass of oil degraded which suggests that a loss of up to $50 \%$ of $\mathrm{C}_{6}$ and above compounds could be correlated to the level of biodegradation [54]. Following this condition, the observed abundance of $\mathrm{C}_{12}-\mathrm{C}_{20}$ compounds in our samples indicated a poor level of biodegradation. Lack of appreciable hydrocarbon bioattenuation (rate and extent of degradation) could be due to one or multiple reasons including paucity of nutrients and other chemicals necessary for microbial metabolism or activation of the hydrocarbons $[10,13,30]$. The test samples were found to be rich in medium or long chain alkanes with branching and substitutions. Most of these hydrocarbons have been reported to be least reactive to oxidation as activation of their $\mathrm{C}-\mathrm{H}$ bonds requires various abiotic factors including high temperature or pressure, UV light or chemical oxidant. [55]. Alvarej and Illman, [56] reported that branching and substitutions increase recalcitrance. Microbial degradation of these compounds requires either oxygen or nitrate, which serves as a reactant for alkane activation and as a TEA. Lack of dissolved oxygen in the present waste could impair the oxygenic activation process and also reduce the overall metabolic requirement due to shift in electron transport processes. Under anaerobic condition, a narrow range of alkane is metabolized by sulfate or nitrate-reducing bacteria and activation of alkanes is done by fumarate addition $[55,57]$. Although relatively higher amounts of sulfate were found in GR1 and DB2, thermodynamically anaerobic hydrocarbon biodegradation coupled with sulfate reduction (dissimilatory sulfate reduction) is considered to be less favored than nitrate or nitrite reduction [58]. In contrast, assimilatory and/or dissimilatory reductions of nitrate or nitrite often facilitate oxidation of organic compounds $[6,59]$. In microaerophilic and anaerobic conditions, nitrate is not only used as TEA (Terminal Electron Acceptor) but also act as an activator of the alkanes facilitating their biodegradation $[55,58]$. High TPH containing anoxyic, mesophillic to slightly thermophillic nature of the test sludge samples resembled with waste generated from various other 

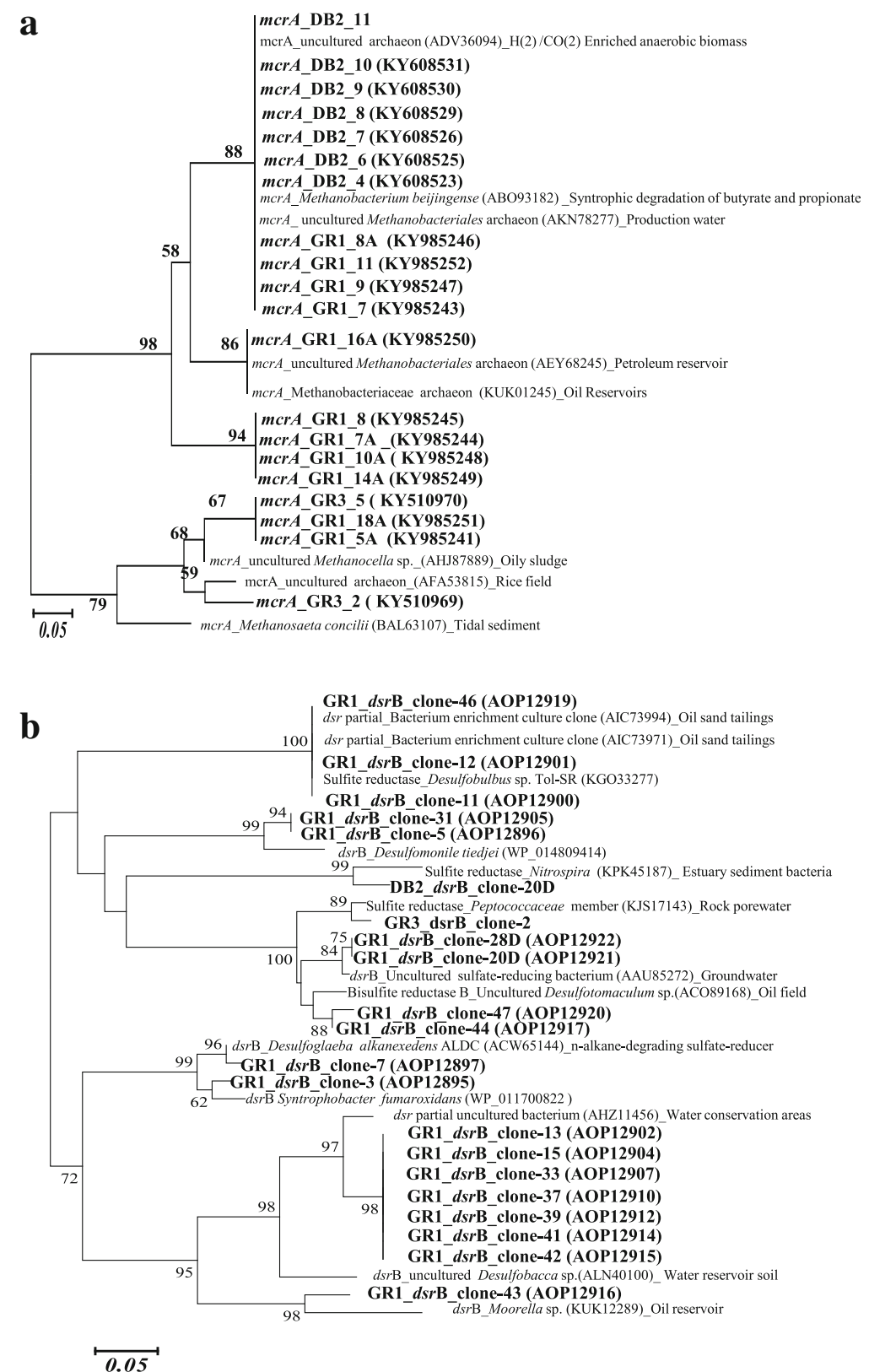

Fig. 10 Phylogenetic tree of functional genes mcrA (a) $d s r B(\mathbf{b})$ based on translated partial amino acid sequences. Trees were constructed using neighbor joining method and bootstrap values $>50 \%$ were indicated at the nodes. One thousand bootstrap analyses were conducted. Scale bar $=0.05$ change per amino acid position

refineries and oil storage facilities $[1,4,6,10,42,60]$. The prevailing conditions could favour growth of methanogenic microorganisms which are on the extreme end of thermodynamic benefits and often depend on metabolic products of anaerobic hydrocarbon degradation (acetate, $\mathrm{CO}_{2}$ and $\mathrm{H}_{2}$ ) produced by bacterial counterpart [15]. However, lack of nitrate, the thermodynamically favoured electron acceptor over sulfate in such oxygen deficient environment impairs the intrinsic bioremediation potential of native microbiome $[54,58,61]$.
Microbiological diversity and other related quantitative parameters (e.g., total cell counts and 16S rRNA gene copy numbers) indicated that in spite of high TPH content and insufficient $\mathrm{N}$ and $\mathrm{P}$ nutrient, the waste sludge harbored rich microbial communities with considerable species diversity and cell abundance. The values of diversity indices, as well as total and cultivable cell counts were comparable with those of various other petroleum producing/contaminated environments (Additional file 4: Table S3) $[8,22,62]$. Relatively higher values of the Shannon 
indices for GR1 and DB2 samples in particular corroborated well with that of refuelling station, oil field and soil contaminated from abandoned oil wells samples (5.5-8.5). The Shannon index of GR3 was slightly low, which could be attributed to the extreme nature with respect to higher temperature and hydrocarbon content of the sample and was found to be in line with production water, injection water and beach sand exposed to deep water horizon spill (3.4-5.2). Phylum level distribution indicated that GR1 and DB2 sludge samples showed resemblance with that of refuelling station. The qPCR analysis indicated an abundance of microbial cells (bacteria and archaea). The copy number of $d s r$ B gene in GR1 $\left(2.2 \times 10^{8} / \mathrm{g}\right)$ or DB2 $(3.5 \times$ $\left.10^{8} / \mathrm{g}\right)$ was almost 10 times higher than that of GR3 $(4 \times$ $\left.10^{7} / \mathrm{g}\right)$. This observation corroborated well with comparatively higher abundance of sulfate-reducers like Coprothermobacter, Thermodesulfovibrio, etc. in GR1 and DB2 than in GR3. Abundance of archaea, in particular could be attributed to the anaerobic, hydrocarbon-rich state of the samples that lack dissolved $\mathrm{O}_{2}$ and other inorganic electron acceptors and catabolically rely on a restricted number of simple compounds, e.g., $\mathrm{CO}_{2}$ as an oxidant with $\mathrm{H}_{2}$ as an electron donor or on acetate, methanol and formate [63]. The observed microbial abundance within these sludge samples presented a contrast to the perception that unlike natural environment with high microbial diversity, hydrocarbon-rich environment containing relatively limited variety of carbon sources will support a lower microbial diversity [21]. Our observation suggests that the inherent toxic effect of hydrocarbons, improper nutritional condition and other physical constraints could not diminish the development of microbial community within refinery sludge. From the intrinsic bioremediation feasibility point of view, a diverse community is preferred, as higher diversity means that a given process could be carried out under a broader range of environmental conditions.

Our study illustrated the community composition of refinery sludge samples and explored the complexity of interactions within the various guilds. All the three samples were found to be mainly colonized by hydrocarbon metabolizing strict anaerobic populations along with a few aerobic bacteria as minor groups. The predominance of Chloroflexi, Firmicutes, Deltaproteobacteria, Thermotogae and Methanobacteria was in accordance with oxygen limited, hydrocarbon-rich, reduced (negative ORP) state of the samples. Members of Chloroflexi have been reported to be involved in the fermentative metabolism of alkanes under anaerobic sulfate-reducing condition and even connected to methanogenesis through reverse electron transport [63, 64]. Role of strictly anaerobic Deltaproteobacteria members (e.g., Syntrophus, Syntrophobacter, Geobacter, etc.) in biodegradation was undoubtedly proven. Members of this taxa have been implicated as one of the most potent group involved in activation and subsequent oxidation of broad range alkanes via long chain fatty acids (LCFA) metabolism to acetate and hydrogen in methanogenic environments [24, 65]. Presence of Firmicutes in anaerobic hydrocarbon degrading communities as a primary biodegrading population has been previously reported [24, 25]. Strict anaerobic members of this phylum are known for biodegradation of broad ranges of alkanes and iso-alkanes under sulfate reducing or methanogenic conditions $[66,67]$. Especially, the abundance of anaerobic, fermentative, thermophilic Coprothermobacter (Firmicutes) capable of producing acetate $/ \mathrm{H}_{2}$ and maintaining of syntrophic association with hydrogenotrophic archaea could be noticed. Coprothermobacter was previously implicated in different anaerobic biodegradation pathways in diverse mesophilic to thermophilic anaerobic sludge [68, 69]. Predominance of hydrogenotrophic Methanobacterium, Methanocella, etc. as the major archaeal populations but fewer acetoclastic methanogens (e.g. Methanosaeta) are in good agreement with the presence of syntrophic, fermentative (mainly hydrogenotrophic), sulfate-reducing bacterial populations. Methanogenic archaea are known to co-exist with fermentative, sulfate-reducing and syntrophic organisms producing simple substrates like $\mathrm{CO}_{2}$, $\mathrm{H}_{2}$, acetate, formate, methanol, etc. [70]. Hydrogenotrophic methanogens maintain low hydrogen concentration within methanogenic hydrocarbon-rich environment thus facilitating the growth of fermenting organisms and hydrocarbon degradation. The abundance of methanogenic archaea and methanogenesis process within the sludge environment was supported by the existence of functional biomarkers mcrA gene. Together with strict anaerobic populations, minor presence of aerobic-microaerophilic groups in refinery wastes corroborate with recent findings on microbial communities in hydrocarbon resource environments $[9,30]$. Presence of aerobic/facultative anaerobic, nitrate reducing Novosphingobium, Paracoccus and Hyphomicrobium (Alphaproteobacteria) was in accordance with previous reports that indicate enhanced denitrification in the presence of methanol and implicate the role of these hydrocarbon metabolizing organisms in the petroleum-rich environments [71-73]. $\mathrm{N}_{2}$ fixing $A z o$ vibrio (Betaproteobacteria), Azospirillum and Rhodobacteria (Alphaproteobacteria) found in nitrogen deficient refinery waste could facilitate the supply of fixed nitrogen essential for community function. Members of Rhodobacteraceae were capable of methane oxidation (forming methanol) and thereby support the metabolism of methanol-utilizing populations [72].

PICRUSt analysis highlighted diverse and complex assemblages of genes related to hydrocarbon degradation, nitrate/sulfate metabolism, fermentation and methane metabolism. Most of the genes were involved in survival processes of bacteria in this particular environment. 
Varied distribution of genes involved in degradation of xenobiotic compounds was observed among the samples with slightly higher in GR3 for xylene, nitrotoluene, naphthalene and benzoate degradation and DB2 for styrene, toluene, bisphenol, fluorobenzoate, chloroalkane and chloroalkene degradation. The predominance of transporter genes especially those involved in the ABC-type transport system which are often present in gene clusters connected to aromatic compound metabolism were observed [36]. Overall, PICRUSt analysis highlighted the degradation potential of wide range of aromatic and aliphatic hydrocarbons and supported the functional group distribution which is in accordance with phylogenetic distribution in such petroleum hydrocarbon-rich environment.

Our observations on microbial ecology of refinery waste sludge highlighted the potential of communities towards mineralization of hydrocarbons through a concerted effort of diverse microbial populations forming functional guilds. Under reducing environment, mineralization of organic compound could be more complex and may require cooperation of different groups of residing microorganisms [34]. Previous investigators have reported Pseudoxanthomaonas, Mycobacterium, Gordonia, Microbacterium, etc., as aerobic hydrocarbon degraders, Novosphigobium, Pseudomonas, Bacillus, Dietzia, etc. as facultative anaerobic degrader and Longilinea, Geobacter, etc. as obligate anaerobic degraders which were also observed in our samples as major microbial groups $[6,9,30,42,61,71,73-$ 75]. It was also been reported that such microorganisms could degrade long chain aliphatics and aromatics into smaller hydrocarbons, which could be further degraded into small acids (butyrate, propionate, acetate, formate, etc.), alcohols (ethanol, methanol, etc.), $\mathrm{CO}_{2}$ and $\mathrm{H}_{2}$ by fermentative microorganisms including Coprothermobacter, Anaerostipes, Paludibacter, Anaerobaculum, Clostridium, Anaerovorax, Syntrophus, etc., as also observed in test sludge samples [25, 69, 76-81]. Rojo et al., [57] reported that in oxygen deficient environment, alkanes could be metabolized by sulfate- or nitrate-reducing bacteria by activating alkanes through the addition of fumarate. Within sludge the community many microbial groups known to be sulfate/thiosulfate- (Coprothermobacter, Anaerobaculum, Thermodesulfovibrio etc.), nitrate- (Gordonia, Novosphigobium, Bacillus, etc.), iron- (Geobacter) and managanese- (Dietzia) reducer were present [6, 42, $61,70,71,77-79]$. It was known that acetate produced by the fermentative organisms could undergo oxidation by syntrophic acetate oxidizers like Clostridium resulting in the formation of $\mathrm{CO}_{2}$ and $\mathrm{H}_{2}$ [80]. The conversion of resultant $\mathrm{CO}_{2}$ and $\mathrm{H}_{2}$ into methane by hydrogenotrophic methanogens like Methanobacterium, Methanocella, etc., was well known phenomenon. Such methanogenic archaea were also found in all the three sludge microbiomes $[9,42,49,81]$. Acetate could be directly converted to methane by acetoclastic methanogens like Methansaeta [50]. Mbadinga et al., [82] stated that formate and hydrogen could also be metabolized by hydrogenotrophic methanogens to methane. In anaerobic environments, methanogenesis could play an important role for the degradation of hydrocarbons in polluted soils, aquifers and oil reservoirs, thus contributing considerably to the mineralization of petroleum hydrocarbons [63]. Methanol produced as fermentation product has been known to be used by methylotrophs like Methylobacterium, Hyphomicrobium, etc. [72]. Reports on few species of Methylobacterium utilizing methane have been also found [83]. Methylosinus a methane oxidizer was also found as a member of sludge microbiome [72]. Varied abundance of these methanogenic, methlytrophic and methanotrophic organisms were observed in all the test sludge samples. The syntrophic association between various fermentative, sulfate-reducing members like Syntrophus, Coprothermobater, Syntrophobacter, Syntrophomonas, etc. with methanogens have been previously reported from oil associated environment $[9,34,68,69,76]$. The close proximity of aerobic and anaerobic bacteria in the petroleum resource environment community was also evident earlier [9]. Although the sludge storage tanks, sampled for this study were grossly anaerobic, our findings suggested presence of both aerobic and anaerobic organisms. The top layer of waste storage tanks were always exposed to air and aerobic bacteria could thrive in such environment. Moreover, convective and diffusive fluxes and rate of reaction of $\mathrm{O}_{2}$ with various organic or inorganic targets often determine the concentration of $\mathrm{O}_{2}$ within the sludge itself. The samples were rich in aliphatic and aromatic hydrocarbons. The readily degradable fractions (oxidizable) of the constituent hydrocarbons consumes available oxygen as electron acceptor resulting in the production of $\mathrm{CO}_{2}$ and other metabolic intermediates, which could further reduce the dissolved oxygen. This might support a cascade of anaerobic metabolism by community members.

\section{Conclusion}

We have explored the microbial community composition of petroleum rich refinery wastes and their catabolic potentials. Refinery sludge microbiomes were comprised of hydrocarbon degrading (Longilina, Mycobacterium, Gordonia, Novosphingobium, Geobacter, etc.) fermentative (Coprothermobacter, Fervidobacterium, Anaerostipes, Anaerobaculum, Clostridium, Anaerovorax, etc.), sulfate-reducing (Coprothermobacter, Anaerobaculum, Thermodesulfovibrio, etc.), syntrophic (Syntrophus, Coprothermobater, Syntrophobacter, etc.), nitrogen fixing (Azovibrio, Rhodobacter, etc.) and methanogenic (Methanobacterium, Methanosaeta, Methanocella, etc.) microorganisms, which are in accordance with the prevailing 
physicochemical nature of the samples. Most of the bacteria capable of anaerobic utilization of hydrocarbons could exist in syntrophic alliance with methanogenic organisms that consume their metabolic end products. Methyl coenzyme $\mathrm{M}$ reductase A ( $m c r \mathrm{~A})$ and dissimilatory sulfite reductase beta-subunit $(d s r \mathrm{~B})$ gene phylogeny confirmed methanogenic and sulfate-reducing activities within sludge environment endowed by hydrogenotrophic methanogens and sulfate-reducing Deltaproteobacteria and Firmicutes members. Overall observation indicated the possibilities of on-site bioremediation of oil refinery sludge exploiting the metabolic interplay of the indigenous microbial populations.

\section{Additional files}

Additional file 1: Table S1. Details of PCR primers and PCR conditions. (DOC $39 \mathrm{~kb}$ )

Additional file 2: Table S2. Detailed hydrocarbon distribution of oily sludge samples. (DOC $73 \mathrm{~kb}$ )

Additional file 3: Figure S1. Rarefaction curves of the three oily sludge samples (GR1, DB2 and GR3) on the basis of OTUs from V3 region based $16 \mathrm{~S}$ rRNA amplicon library. (PPTX $42 \mathrm{~kb}$ )

Additional file 4: Table S3. Comparison of major alpha diversity parameters among various hydrocarbon rich samples. (DOC $76 \mathrm{~kb}$ )

Additional file 5: Figure S2. Venn diagram of unique and shared taxa. Unique and shared taxa distribution between 3 samples at OTU level and subsequently at phyla, class, family and genus level showed as Venn diagram. (PPTX $270 \mathrm{~kb}$ )

Additional file 6: Figure S3. Distribution of minor phyla with cumulative abundance of $<0.5$. (PPTX $43 \mathrm{~kb}$ )

Additional file 7: Figure S4. Heat map indicating the relative abundance of minor genera with cumulative abundance of $0.1-0.01 \%$. (PPTX $364 \mathrm{~kb}$ )

Additional file 8: Figure S5. Phylogentic tree representing of clade1 of top 50 most abundant OTUs. Tree was constructed using the neighbour joining method incorporating Jukes-Cantor distance corrections. One thousand bootstrap analyses were conducted and bootstrap values $>50 \%$ were indicated at the nodes. Scale bar $=0.05$ change per nucleotide position. The values in bracket indicated abundance in following the sequence of GR1/DB2/GR3. (PPTX $91 \mathrm{~kb}$ )

Additional file 9: Figure S6. Phylogentic tree representing of clade 2 of top 50 most abundant OTUs. Tree was constructed using the neighbour joining method incorporating Jukes-Cantor distance corrections. One thousand bootstrap analyses were conducted and bootstrap values $>50 \%$ were indicated at the nodes. Scale bar $=0.02$ change per nucleotide position. The values in bracket indicated abundance in following the sequence of GR1/DB2/GR3. (PPTX $74 \mathrm{~kb}$ )

Additional file 10: Figure S7. Phylogentic tree representing of clade 3 of top 50 most abundant OTUs. Tree was constructed using the neighbour joining method incorporating Jukes-Cantor distance corrections. One thousand bootstrap analyses were conducted and bootstrap values $>50 \%$ were indicated at the nodes. Scale bar $=0.02$ change per nucleotide position. The values in bracket indicated abundance in following the sequence of GR1/DB2/GR3. (PPTX $74 \mathrm{~kb}$ )

Additional file 11: Figure S8. Phylogentic tree representing of clade 4 of top 50 most abundant OTUs. Tree was constructed using the neighbour joining method incorporating Jukes-Cantor distance corrections. One thousand bootstrap analyses were conducted and bootstrap values $>50 \%$ were indicated at the nodes. Scale bar $=0.05$ change per nucleotide position. The values in bracket indicated abundance in following the sequence of GR1/DB2/GR3. (PPTX $54 \mathrm{~kb}$ )
Additional file 12: Table S4. Details of different hydrocarbon contaminated samples considered for comparative analysis. (DOCX $12 \mathrm{~kb}$ )

Additional file 13: Table S5. Detailed distribution of predictive genes within sludge metagenomes using PICRUSt. (DOC $87 \mathrm{~kb}$ )

\section{Abbreviations}

AWCD: Average Well Color Development; CLPP: Community level physiological profiling; DO: Dissolved Oxygen; dsrB: Dissimilatory sulfite reductase betasubunit; KEGG: Kyoto Encyclopedia of Genes and Genomes; mcrA: Methyl coenzyme M reductase A; NSTI: Nearest Sequenced Taxon Index; ORP: Oxidation Reduction Potential; OTU: Operation Taxonomic Unit; PICRUSt: Phylogenetic Investigation of Communities by Reconstruction of Unobserved States; QIIME: Quantitative Insights into Microbial Ecology; qPCR: Quantitative Polymearse Chain Reaction; TPH: Total Petroleum Hydrocarbon; UPGMA: Unweighted Pair Group Method with Arithmetic Mean

\section{Acknowledgments}

Generous support from Guwahati and Digboi refineries, Assam, India (Indian Oil Corporation Limited) in providing refinery waste samples is gratefully acknowledged.

\section{Funding}

This work was funded by Department of Biotechnology, Government of India under NER Twinning project (BT/226/NE/TBP/2011). The funding bodies had no role in the design of the study, collection, analysis and interpretation of data and in writing the manuscript.

\section{Availability of data and materials}

The raw reads were deposited to the NCBI Sequence Read Archive database (SRA) under accession numbers SRS1075014, SRX1257709 and SRR2643899 for GR1 V3; SRS1113836, SRX1334517 and SRR2646856 for DB2 V3 and SRS1113581, SRX1333895 and SRR2645287 for GR3_V3 (Bioproject ID: PRJNA289742). The archaebacterial clone sequences have been submitted to NCBI database under accession numbers KX503371-KX503381 (GR1), KY558575-KY558583 (GR3) and KX503382-KX503388 (DB2). The mcrA and dsrB clone sequences obtained were submitted in NCBI database [accession numbers KY985241- KY985252 (mcrA, GR1); KY510968-KY510975 (mcrA, GR3); KY608522-KY608531 (mcrA, DB2); KX787854-KX787882 (dsrB, GR1); KY608532KY608537 (dsrB, DB2)]

\section{Authors' contribution}

SK and P Sar conceived the idea of the work, designed the experiments, arranged funds and other logistics and supervised. AR, JS and PS performed the major experiments. AR, JS, AD, P Sar and SK were responsible for manuscript preparation. AR, SP, P Sar and SK were responsible for sampling the oily waste sludge from refineries. AR, JS, PS, AG and BM were responsible for optimization of PCR conditions and analysis of functional genes. $A D$, JS and AR performed bioinformatic and statistical analyses. All authors read and approved the manuscript.

\section{Competing interest}

The author declares that they have no competing interests.

Ethics approval and consent to participate

Not applicable.

\section{Consent for publication}

Not applicable.

\section{Publisher's Note}

Springer Nature remains neutral with regard to jurisdictional claims in published maps and institutional affiliations.

\section{Author details}

'Department of Biotechnology, National Institute of Technology Durgapur, Durgapur, WB 713 209, India. ${ }^{2}$ Department of Biotechnology, Indian Institute of Technology Kharagpur, Kharagpur, WB 721 302, India. ${ }^{3}$ School of Bioscience, Indian Institute of Technology Kharagpur, Kharagpur, WB 721302 India. 
Received: 14 March 2018 Accepted: 28 September 2018

Published online: 22 October 2018

\section{References}

1. Hu G, Li J, Zeng G. Recent development in the treatment of oily sludge from petroleum industry: a review. J Hazard Mater. 2013;261:470-90.

2. Fuentes S, Barra B, Caporaso JG, Seeger M. From rare to dominant: a finetuned soil bacterial bloom during petroleum hydrocarbon bioremediation. Appl Environ Microbiol. 2016;82(3):888-96.

3. Liu Q, Tang J, Bai Z, Hecker M, Giesy JP. Distribution of petroleumdegrading genes and factor analysis of petroleum-contaminated soil from the Dagang oilfield, China. Sci Rep. 2015;5:11068.

4. Bhattacharyya JK, Shekdar AV. Treatment and disposal of refinery sludges: Indian scenario. Waste Manage Res. 2003;21:249-61.

5. Suja F, Rahim F, Taha MR, Hambali N, Razali MR, Khalid A, Hamzah A. Effects of local microbial bioaugmentation and biostimulation on the bioremediation of total petroleum hydrocarbons (TPH) in crude oil contaminated soil based on laboratory and field observations. Int. Biodeter. Biodegr. 2014;90:115-22.

6. Sarkar J. Kazy SK, Gupta a, Dutta a, Mohapatra B, Roy a, Bera P, Mitra a, Sar P. Biostimulation of indigenous microbial community for bioremediation of petroleum refinery sludge. Front. Microbiol. 2016;7(1407):1-20.

7. Lu Q, Luo QS, Li H, Liu YD, Gu JD, Lin KF. Characterization of chlorinated aliphatic hydrocarbons and environmental variables in a shallow groundwater in Shanghai using kriging interpolation and multifactorial analysis. PLoS One. 2015;10(11):e0142241.

8. Yang S, Wen X, Shi Y, Liebner S, Jin H, Perfumo A. Hydrocarbon degraders establish at the costs of microbial richness, abundance and keystone taxa after crude oil contamination in permafrost environments. Sci Rep. 2016;6:37473.

9. An D, Caffrey SM, Soh J, Agrawal A, Brown D, Budwill K, et al. Metagenomics of hydrocarbon resource environments indicates aerobic taxa and genes to be unexpectedly common. Environ Sci Technol. 2013;47:10708-17.

10. Head IM, Gray ND, Larter SR. Life in the slow lane; biogeochemistry of biodegraded petroleum containing reservoirs and implications for energy recovery and carbon management. Front Microbiol. 2014;5(566):1-23.

11. Duran R, Cravo-Laureau C. Role of environmental factors and microorganisms in determining the fate of polycyclic aromatic hydrocarbons in the marine environment. FEMS Microbiol Rev. 2016;40:814-30.

12. Cerqueira VS, Hollenbach EB, Maboni F, Vainstein MH, Camargo FAO, Peralba MCR, Bento FM. Biodegradation potential of oily sludge by pure and mixed bacterial cultures. Bioresour Technol. 2011;102:11003-10.

13. Smith E, Thavamani P, Ramadass K, Naidu R, Srivastava P, Megharaj M. Remediation trials for hydrocarbon-contaminated soils in arid environments: evaluation of bioslurry and biopiling techniques. Int Biodeter Biodegr. 2015; 101:56-65.

14. Zhang Z, Lo IM. Biostimulation of petroleum-hydrocarbon contaminated marine sediment with co-substrate: involved metabolic process and microbial community. Appl Microbiol Biotechnol. 2015;99:5683-96.

15. Kobayashi H, Endo K, Sakata S, Mayumi D, Kawaguchi H, Ikarashi M, Miyagawa Y, Maeda H, Sato K. Phylogenetic diversity of microbial communities associated with the crude-oil, large insoluble-particle and formation-water components of the reservoir fluid from a non-flooded high-temperature petroleum reservoir. J Biosci Bioeng. 2012;113:204-10.

16. Daffonchio D, Ferrer M, Mapelli F, Cherif A, Lafraya A, Malkawi HI, et al. Bioremediation of southern Mediterranean oil polluted sites comes of age. New Biotechnol. 2013;30:743-8.

17. Hazen TC, Rocha AM, Techtmann SM. Advances in monitoring environmental microbes. Curr Opin Biotechnol. 2013;24:526-33.

18. Ghosal D, Ghosh S, Dutta TK, Ahn Y. Current state of knowledge in microbial degradation of polycyclic aromatic hydrocarbons (PAHs). rev Front Microbiol. 1369;7:2016.

19. Kostka JE, Prakash O, Overholt WA, Green SJ, Freyer G, Canion A, Delgardio J, Norton N, Hazen TC, Huettel M. Hydrocarbon degrading bacteria and the bacterial community response in Gulf of Mexico beach sands impacted by the Deepwater horizon oil spill. Appl Environ Microbiol. 2011;77(22):7962-74.

20. Bell TH, Yergeau E, Martineau C, Juck D, Whyte LG, Greer CW. Identification of nitrogen incorporating bacteria in petroleum-contaminated Arctic soils by using $\left[{ }^{15} \mathrm{~N}\right]$ DNA-based stable isotope probing and pyrosequencing. Appl Environ Microbiol. 2011;77(12):4163-71.

21. Yergeau E, Lawrence JR, Sanschagrin S, Waiser MJ, Korber DR, Greer CW. Next generation sequencing of microbial communities in the Athabasca river and its tributaries in relation to oil sands mining activities. Appl Environ Microbiol. 2012;78(21):7626-37.

22. Lamendella R, Strutt S, Borglin S, Chakraborty R, Tas N, Mason OU, Hultman J, Prestat $\mathrm{E}$, Hazen TC, Jansson JK. Assessment of the Deepwater horizon oil spill impact on gulf coast microbial communities. Front Microbiol. 2014;5:130.

23. Liao J, Wang J, Huang Y. Bacterial community features are shaped by geographic location, physicochemical properties, and oil contamination of soil in main oil fields of China. Environ Microbiol. 2015;70:380-9.

24. Tan B, Fowler SJ, Laban NA, Dong X, Sensen CW, Foght J, Gieg LM. Comparative analysis of metagenomes from three methanogenic hydrocarbon-degrading enrichment cultures with 41 environmental samples. ISME J. 2015;9(9):2028-45.

25. Fowler SJ, Toth CRA, Gieg LM. Community structure in methanogenic enrichments provides insight into syntrophic interactions in hydrocarbonimpacted environments. Front Microbiol. 2016;7(562):1-13.

26. Gao P, Tian H, Li G, Sun H, Ma T. Microbial diversity and abundance in the Xinjiang Luliang long-term water-flooding petroleum reservoir. Microbiol Open. 2015;4(2):332-42.

27. VanMensel D, Chaganti SR, Boudens R, Reid T, Ciborowski J, Weisener C. Investigating the microbial degradation potential in oil sands fluid fine tailings using gamma irradiation: a metagenomic perspective. Microb Ecol. 2017;74(2):362-72.

28. Sarkar P, Roy A, Pal S, Mohapatra B, Kazy SK, Maiti MK, Sar P. Enrichment and characterization of hydrocarbon-degrading bacteria from petroleum refinery waste as potent bioaugmentation agent for in situ bioremediation. Bioresour Technol. 2017;242:15-27.

29. Hu P, Tom L, Singh A, Thomas BC, Baker BJ, Piceno YM, Andersen GL, Banfield JF. Genome-resolved metagenomic analysis reveals roles for candidate phyla and other microbial community members in biogeochemical transformations in oil reservoirs. mBio. 2016;7(1):e01669-15.

30. Fathepure BZ. Recent studies in microbial degradation of petroleum hydrocarbons in hyper saline environments. Front Microbiol. 2014;5(173):1-16.

31. Stagars MH, Mishra S, Treude T, Amann R, Knitte K. Microbial community response to simulated petroleum seepage in Caspian Sea sediments. Front Microbiol. 2017;8(764):1-16.

32. Baldwin $B R$, Nakatsu $C H$, Nies L. Detection and enumeration of aromatic oxygenase genes by multiplex and real-time PCR. Appl Environ Microbiol. 2003:69(6):3350-8.

33. Kazy SK, Monier AL, Alvarej PJ. Assessing the correlation between anaerobic toulene degradation activity and bssA concentrations in hydrocarbon contaminated aquifer material. Biodegradation. 2010;21(5):793-800.

34. Kleinsteuber S, Schleinitz KM, Vogt C. Key players and team play: anaerobic microbial communities in hydrocarbon-contaminated aquifers. Appl Microbiol Biotechnol. 2012;94:851-73.

35. Fuentes S, Méndez V, Aguila P, Seeger M. Bioremediation of petroleum hydrocarbons: catabolic genes, microbial communities and applications. Appl Microbiol Biotechnol. 2014;98:4781-94.

36. Sierra-García IN, Alvarez CJ, de Vasconcellos SP, Pereira de Souza A, dos Santos Neto EV, de Oliveira VM. New hydrocarbon degradation pathways in the microbial metagenome from Brazilian petroleum reservoirs. PLoS One. 2014;9:e90087.

37. Guibert LM, Loviso CL, Borglin S, Jansson JK, Dionisi HM, Lozada M. Diverse bacterial groups contribute to the alkane degradation potential of chronically polluted subantarctic coastal sediments. Microb Ecol. 2016;71:100-12.

38. Vigneron A, Alsop EB, Lomans BP, Kyrpides NC, Head IM, Tsesmetzi N. Succession in the petroleum reservoir microbiome through an oil field production lifecycle. ISME J. 2017;11(9):2141-54.

39. Guerra AB, Oliveira JS, et al. Metagenome enrichment approach used for selection of oil-degrading bacteria consortia for drill cutting residue bioremediation. Environ Pollut. 2018:235:869-80.

40. Dombrowski N, Seitz KW, Teske AP, Baker JB. Genomic insights into potential interdependencies in microbial hydrocarbon and nutrient cycling in hydrothermal sediments. Microbiome. 2017;5(106):1-13.

41. Kepner RL, Pratt JR. Use of fluorochromes for direct enumeration of total bacteria in environmental samples: past and present. Microbiol Rev. 1994;58:603-15.

42. Das R, Kazy SK. Microbial diversity, community composition and metabolic potential in hydrocarbon contaminated oily sludge: prospects for in situ bioremediation. Environ Sci Pollut Res. 2014;21:7369-89.

43. Caporaso JG, Kuczynski J, Stombaugh J, Bittinger K, Bushman FD, Costello EK, et al. QIIME allows analysis of highthroughput community sequencing data. Nat Methods. 2010;7:335-6. 
44. Bartram AK, Lynch MDJ, Stearns JC, Hagelsieb GH, Neufeld JD. Generation of multimillion-sequence 165 rRNA gene libraries from complex microbial communities by assembling paired-end Illumina reads. Appl Environ Microbiol. 2011;77(11):3846-52.

45. Schloss PD, Westcott SL, Ryabin T, Hall JR, Hartmann M, Hollister EB, Sahl JW. Introducing MOTHUR: open-source, platform-independent, communitysupported software for describing and comparing microbial communities. Appl Environ Microbiol. 2009;75(23):7537-41.

46. Arndt D, Xia J, Liu Y, Zhou Y, Guo AC, Cruz JA, Wishart DS. METAGENassist: a comprehensive web server for comparative metagenomics. Nucleic Acids Res. 2012:40:W88-95.

47. Langille MG, Zaneveld J, Caporaso JG, McDonald D, Knights D, Reyes JA, Beiko RG. Predictive functional profiling of microbial communities using $16 \mathrm{~S}$ rRNA marker gene sequences. Nat Biotechnol. 2013;31(9):814-21.

48. Tamura K, Peterson D, Peterson N, Stecher G, Nei M, Kumar S. MEGA5: molecular evolutionary genetics analysis (MEGA) using maximum likelihood, evolutionary distance and maximum parsimony methods. Mol Biol Evol. 2011;28(10):2731-9.

49. Ma K, Liu X, Dong X. Methanobacterium beijingense sp. nov., a novel methanogen isolated from anaerobic digesters. Int J Syst Evol Microbiol. 2005:55:325-9.

50. Barber RD, Zhang L, Harnack M, Olson MV, Kaul R, Ingram-Smith C, et al. Complete genome sequence of Methanosaeta concilii, a specialist in aceticlastic methanogenesis. J Bacteriol. 2011;193:3668-9.

51. Kamagata Y, Kawasaki H, Oyaizu H, Nakamura K, Mikami E, Endo G, et al. Characterization of three thermophilic strains of Methanothrix ("Methanosaeta") thermophila sp. nov., and rejection of Methanothrix ("Methanosaeta") thermoacetophila. Int J Syst Bacteriol. 1992;42:463-8.

52. Imachi H, Sakai S, Sekiguchi Y, Hanada S, Kamagata Y, Ohashi A, Harada H. Methanolinea tarda gen. Nov., sp. nov., a methane producing archaeon isolated from a methanogenic digester sludge. Int J Syst Evol Microbiol. 2007;58:294-301.

53. Bell TH, Yergeau E, Maynard C, Juck D, Whyte LG, Greer CW. Predictable bacterial composition and hydrocarbon degradation in arctic soils following diesel and nutrient disturbance. ISME J. 2013;7:1200-10.

54. Head IM, Jones DM, Larter SR. Biological activity in the deep subsurface and the origin of heavy oil. Nature. 2003;426:344-52.

55. Callaghan AV, Tierney M, Phelps CD, Young LY. Anaerobic biodegradation of $n$-hexadecane by a nitrate-reducing consortium. Appl Environ Microbiol 2009;75(5):1339-44.

56. Alvarez PJJ, IIIman WA. Biodegradation principle. Bioremediation and natural attenuation: process fundamentals and mathematical models. John Wiley and Sons. Inc. 2005;3:49-114

57. Rojo F. Degradation of alkanes by bacteria. Environ Microbiol. 2009;11:2477-90.

58. Zedelius J, Rabus R, Grundmann O, Werner I, Brodkorb D, Schreiber F, et al. Alkane degradation under anoxic conditions by a nitrate-reducing bacterium with possible involvement of the electron acceptor in substrate activation. Environ Microbiol Rep. 2011;3:125-35.

59. Xu M, Zhang Q, Xia C, Zhong Y, Sun G, Guo J, Yuan T, Zhou J, Zhili HZ. Elevated nitrate enriches microbial functional genes for potential bioremediation of complexly contaminated sediments. ISME J. 2014;8:1932-44.

60. Ze Bilo'o P, Ngassoum MB, Solange C, Ekoka J. Characterization of oily sludge from Cameroon petroleum refinery. Int J Emerging Engineering Res Technol. 2016;4:34-8.

61. Varjani SJ. Microbial degradation of petroleum hydrocarbons. BioresourTechnol. 2017;223:277-86.

62. Kasai Y, Kishira H, Syutsubo K, Harayama S. Molecular detection of marine bacterial populations on beaches contaminated by the Nakhodka tanker oilspill accident. Environ Microbiol. 2001;3:246-55.

63. Kleikemper J, Pombo SA, Schroth MH, Sigler WS, Pesaro M, Zeyer J. Activity and diversity of methanogens in a petroleum hydrocarbon-contaminated aquifer. Appl Environ Microbiol. 2005;71(1):149-58.

64. Narihiro T, Terada T, Ohashi A, Kamagata Y, Nakamura K, Sekiguchi Y. Quantitative detection of previously characterized syntrophic bacteria in anaerobic wastewater treatment systems by sequence-specific rRNA cleavage method. Water Res. 2012;46:2167-75.

65. Xia Y, Wang Y, Wang Y, Chin FYL, Zhang T. Cellular adhesiveness and cellulolytic capacity in Anaerolineae revealed by omics-based genome interpretation. Biotechnol Biofuels. 2016;9:111.
66. Fowler SJ, Gutierrez-Zamora ML, Manefield M, Gieg LM. Identification of toluene degraders in a methanogenic enrichment culture. FEMS Microbia Ecol. 2014;89:625-36.

67. Tan B, Charchuk R, Li C, Nesbø C, Laban AN, Foght J. Draft genome sequence of uncultivated Firmicutes (Peptococcaceae SCADC) single cells sorted from methanogenic alkane-degrading cultures. Genome Announc. 2014;2:e00909-14.

68. Mayumi D, Mochimaru H, Yoshioka H, Sakata S, Maeda H, Miyagawa Y, Ikarashi M, Takeuchi M, Kamagata Y. Evidence for syntrophic acetate oxidation coupled to hydrogenotrophic methanogenesis in the hightemperature petroleum reservoir of Yabase oil field (Japan). Environ Microbiol. 2011;13:1995-2006.

69. Gagliano MC, Braguglia CM, Petruccioli M, Rossetti S. Ecology and biotechnological potential of the thermophilic fermentative Coprothermobacter spp. FEMS Microbiol Ecol. 2015;91:1-12.

70. Andrews KT, Patel BKC. Fervidobacterium gondwanense sp. nov., a new thermophilic anaerobic bacterium isolated from non-volcanically heated geothermal waters of the great Artesian Basin of Australia. Int J Syst Evol Microbiol. 1996:46:265-9.

71. Sohn JH, Kwon KK, Kang JH, Jung HB, Kim SJ. Novosphingobium pentaromativorans sp. nov., a high-molecular-mass polycyclic aromatic hydrocarbon-degrading bacterium isolated from estuarine sediment. Int J Syst Evol Microbiol. 2004:54:1483-7

72. Chistoserdova L, Kalyuzhnaya MG, Lidstrom ME. The expanding world of methylotrophic metabolism. Annu Rev Microbiol. 2009;63:477-99.

73. Lau MCY, Kieft TL, Kuloyo O, et al. An oligotrophic deep-subsurface community dependent on syntrophy is dominated by sulfur-driven autotrophic denitrifiers. Proc Nat Acad Sci. 2016;113(49):E7927-36.

74. Arenskötter M, Bröker D, Steinbüchel A. Biology of the metabolically diverse genus Gordonia. Appl Environ Microbiol. 2004;70(6):3195-204.

75. Chen MY, Tsay SS, Chen KY, Shi YS, Lin YT, Lin GH. Pseudoxanthomonas taiwanensis sp. nov., a novel thermophilic, $\mathrm{N}_{2} \mathrm{O}$-producing species isolated from hot springs. Int J Syst Evol Microbiol. 2002;52(6):2155-61.

76. Gray ND, Sherry A, Grant RJ, Rowan AK, Hubert CRJ, Callbeck CM, Aitken CM, Jones DM, Adams JJ, Larter SR, Head IM. The quantitative significance of Syntrophaceae and syntrophic partnerships in methanogenic degradation of crude oil alkane. Environ Microbiol. 2011:13:2957-75.

77. Matthies C, Evers S, Ludwig W, Schink B. Anaerovorax odorimutans gen. Nov., sp. nov., a putrescine-fermenting, strictly anaerobic bacterium. Int J Syst Evol Microbiol. 2000;50(4):591-1594.

78. Müller S, Vogt C, Laube M, Harms H, Kleinsteuber S. Community dynamics within a bacterial consortium during growth on toluene under sulfatereducing conditions. FEMS Microbiol Ecol. 2009;70(3):586-96.

79. Eeckhaut V, Vanlmmerseel F, Pasmans F, DeBrandt E, Haesebrouck F, Ducatelle R, Vandamme P. Anaerostipes butyraticus sp. nov., an anaerobic, butyrate-producing bacterium from Clostridium cluster XIVa isolated from broiler chicken caecal content, and emended description of the genus Anaerostipes. Int J Syst Evol Microbiol. 2010;60(5):1108-12.

80. Westerholma M, Moestedt J, Schnürer A. Biogas production through syntrophic acetate oxidation and deliberate operating strategies for improved digester performance. Appl Energy. 2016;179(2016):124-35.

81. Sakai S, Imachi H, Hanada S, Ohashi A, Harada H, Kamagata Y. Methanocella paludicola gen. Nov., sp. nov., a methane-producing archaeon, the first isolate of the lineage 'Rice cluster I', and proposal of the new archaeal order Methanocellales Ord. Nov. Int J Syst Evol Microbiol. 2008;58:929-36.

82. Mbadinga SM, Li KP, Zhou L, Wang LY, Yang SZ, Liu JF, Gu JD, Mu BZ. Analysis of alkane-dependent methanogenic community derived from production water of a high-temperature petroleum reservoir. Appl Microbio Biotechnol. 2012;962:531-42. https://doi.org/10.1007/s00253-011-3828-8.

83. Aken BV, Peres CP, Doty SL, Yoon JM, Schnoor JL. Methylobacterium populi sp. nov., a novel aerobic, pink-pigmented, facultatively methylotrophic, methane-utilizing bacterium isolated from poplar trees (Populus deltoids $\mathrm{x}$ nigra DN34). Int J Syst Evol Microbiol. 2004;54:1191-6. 